\title{
Intraday patterns of price clustering in Bitcoin
}

\author{
Donglian $\mathrm{Ma}^{1^{*}}$ (I) and Hisashi Tanizaki
}

\section{*Correspondence:}

donglian.ma@foxmail.com

${ }^{1}$ Shenzhen Audencia

Business School, Shenzhen

University, Shenzhen 518060

China

Full list of author information

is available at the end of the

article

\begin{abstract}
In this study, an investigation is conducted into the phenomenon of price clustering in Bitcoin (BTC) denominated in the Japanese yen (JPY). It answers two questions using tick-by-tick data. The first is whether price clustering exists in BTC/JPY transactions, and the other is how the scale of price clustering varies throughout a trading day. With the assistance of statistical measures, the last two digits of BTC price were discovered to cluster at the numbers that end with '00'. In addition, the scales of BTC/JPY clustering at ' 00 'tended to decline at the specific hour intervals. This study contributes to the emerging literature on price clustering and investor behavior.
\end{abstract}

Keywords: BTC, Price clustering, Intraday pattern, Tick-by-tick

JEL Classification: G14, G40

\section{Introduction}

Due to a friendly attitude toward cryptocurrencies and sound regulatory policies, Japan has become one of the biggest cryptocurrency markets in the world, with the support from its legal system. On March 7, 2014, the Japanese government officially decided that BTC would not be a currency. Later, it recognized BTC as a legal property under the Payment Services Act (PSA) in April 2017. Most BTCs in Japan are traded as assets in online exchanges rather than as currency paid for goods or services. In addition, exchanges that provide cryptocurrency exchanging services in Japan should be registered and under the regulation of the Financial Services Agency (FSA).

Owing to market segmentation caused by geography and regulations, studies on BTC trading in Japan, especially the features of prices, are inadequate. Japan has been known as a cash society, and cash payments still play an important role in day-to-day transactions (see Fujiki and Tanaka 2018). However, cashless payments are essential for adopting crypto assets because crypto asset transactions in online crypto exchanges or wallets are usually settled through cashless payments. Also, credit or debit cards and mobile payments via smartphones are important in depositing/withdrawing money into/from the accounts of crypto exchanges or wallets. Based on the data of the Financial Literacy Survey, Fujiki (2020) outlined that owners of crypto assets in Japan have several characteristics that distinguish them from those who have not adopted crypto assets, including a higher likelihood

(c) The Author(s) 2022, Open Access This article is licensed under a Creative Commons Attribution 4.0 International License, which permits use, sharing, adaptation, distribution and reproduction in any medium or format, as long as you give appropriate credit to the original author(s) and the source, provide a link to the Creative Commons licence, and indicate if changes were made. The images or other third party material in this article are included in the article's Creative Commons licence, unless indicated otherwise in a credit line to the material. If material is not included in the article's Creative Commons licence and your intended use is not permitted by statutory regulation or exceeds the permitted use, you will need to obtain permission directly from the copyright holder. To view a copy of this licence, visit http:// creativecommons.org/licenses/by/4.0/. 
of having higher pretax income, being male, being under 30, being graduate school graduates, and having an employment status of working in private or public companies, or selfemployed. In this context, this study investigates the price clustering of BTC traded in Japan.

Price clustering is a well-known circumstance in which prices cluster at round or some specific ending numbers. And it has been discovered in different financial markets worldwide. Price clustering has crucial implications in the financial market. First, price clustering impacts spread, which can make a difference to price discovery. If asset prices cluster at round or specific numbers, it is possible that transaction prices do not reflect the underlying value of assets. Consequently, price clustering can affect the distribution of asset returns. When price movements are not randomized, the distribution hypothesis, usually a normal distribution, can potentially be biased. Furthermore, moment estimators such as volatility are possibly influenced by price clustering (Bhattacharya et al. 2012; Blau and Griffith 2016).

This study aims to determine how the price clustering occurs in BTC/JPY, which is considered a financial asset. It answers two questions using tick-by-tick data. The first is whether price clustering exists in BTC/JPY transactions. The other is the extent to which price clustering changes throughout the trading day. Ohta (2006) has demonstrated that, the time-of-day patterns exist in price clustering on the Tokyo Stock Exchange with market opening and closing. In this study, considering that BTC is traded online for 24 hours daily, an attempt is made to verify whether the intraday or hour-of-the-day effects can be manifested in BTC transactions, which aims to determine when an investor is more likely to make decisions that can induce price clustering.

This study contributes to the existing literature on BTC and price clustering in twofold. First, it examines the existence of price clustering in BTC denominated in the JPY rather than the United States Dollar (USD). To date, BTC/USD data have been applied in numerous existing studies on the price clustering of cryptocurrencies, with the data collected from Bitstamp in particular, including Urquhart (2017), Mbanga (2019), Hu et al. (2019), Li et al. (2020), and Baig et al. (2019a). Since the BTC markets other than BTC/USD have been limitedly studied, this study adds to the empirical findings in this research area. Second, this study explores the intraday or hour-of-the-day patterns of price clustering. As numerous traditional asset transactions were conducted during the daytime, few studies compare trading behavior between day and night. Although BTC is traded throughout the day, the empirical results obtained from this study indicate that the scale of BTC/JPY price clustering varies over time.

The remainder of this study is structured as follows. In Section 2, the literature on price clustering and explanations is briefly reviewed. In Section 3, the data and methodology applied in this study are described. In Section 4, the empirical results are presented, including examinations of price clustering throughout the trading day. In Section 5, discussions are conducted about how to account for the intraday pattern of price clustering and strategic pricing based on price clustering. Finally, Section 6 concludes the study. 


\section{Literature review}

\section{Price clustering}

As an anomaly in the financial market, price clustering has a long history. Price clustering was initially detected in the US stock market (Osborne 1962, 1965; Niederhoffer 1965; Harris 1991; Christie and Schultz 1994). They found that stock prices clustered more at round numbers, halves, and quarters in the US stock market, which is inconsistent with the random walk theory. Subsequently, the report on it emerged from other stock markets such as the Australian Stock Exchange (Aitken et al. 1996), the Stock Exchange of Hong Kong (Ahn et al. 2005), the Amsterdam Stock Exchange (Sonnemans 2006), the Tokyo Stock Exchange (Ohta 2006; Aşçloğlu et al. 2007), and so on. Afterward, this phenomenon has also been discovered in foreign exchange markets (Sopranzetti and Datar 2002), future markets (Ap Gwilym et al. 1998; Schwartz et al. 2004; Chun and Chiang 2006; Narayan et al. 2011; Dowling et al. 2016), gold markets (Ball et al. 1985; Aggarwal and Lucey 2007), commodity markets (Palao and Pardo 2012; Brooks et al. 2013), and betting markets (Brown and Yang 2016).

Although price clustering on round numbers or specific integers is commonly observed, clustering on decimal increments in stock markets has also been frequently studied. Given that the US stock market changed price quotes from a fractional system to a decimalization system in 2001, Ikenberry and Weston (2008) found that the level of price clustering at increments of five and ten cents in NYSE and NASDAQ increased during the post-decimalization. Then, Davis et al. (2014) reported the same clustering on prices ending with five or zero from 120 stocks listed on the NASDAQ during 2009. Similarly, Das and Kadapakkam (2020) presented significant clustering at prices ending with zero or five cents of S\&P 500 index stocks from 2001 to 2010. However, Bhattacharya et al. (2012) documented the cluster undercutting effect in decimal increments using data from 2001 to 2006. Specifically, Bhattacharya et al. (2012) observed excess buying at prices which are one penny below round numbers and excess selling at prices which are one penny above round numbers. Outside the US stock market, Sonnemans (2006) found evidence of odd pricing that price is decided at numbers just below some round numbers following the empirical findings in the Dutch stock market from 1990 to 2001. Furthermore, Verousis and Ap Gwilym (2013) showed strong price clustering at numbers ending with decimals of $0.25,0.50$, and 0.75 or integers in the upstairs (off-book) market at the London Stock Exchange in 2005. Later, Verousis and Ap Gwilym (2014) found a cluster undercutting around focal numbers adopted by market makers in the upstairs market at the London Stock Exchange during 2005. Verousis and Ap Gwilym (2014) argued that cluster undercutting is due to the price anchoring and adjustment effects.

Recently, price clustering has also occurred in cryptocurrency markets. Though being designed to be a peer-by-peer electronic payment system (Nakamoto 2008), BTC, the first blockchain cryptocurrency, is usually traded as a financial asset in online exchanges. Urquhart (2017) investigated the daily closing prices of BTC/USD on Bitstamp, which induced the finding that prices first tended to cluster at whole numbers, followed by prices ending with digits of 0.99 and 0.50. Following Urquhart (2017), Mbanga (2019) reported that the extent of BTC closing price clustering at whole numbers is reduced on Monday and increased on Friday from the same exchange. After exploring the historical 
transaction prices from Bitstamp, Hu et al. (2019) discovered that prices cluster at round numbers in cryptocurrencies throughout the day. Based on Urquhart (2017) and $\mathrm{Hu}$ et al. (2019), Li et al. (2020) provided evidence to suggest the occurrence of price clustering for open, high, and low prices using BTC/USD from Bitstamp with varying frequencies. Also, an extraordinary level of price clustering in BTC/USD was found in Baig et al. (2019a) with tick-by-tick transaction data from the five active exchanges.

\section{Explanations for price clustering}

As the existence of price clustering contradicts the random walk hypothesis of financial asset prices, some explanations exist to account for price clustering in traditional financial markets in general. Broadly speaking, these explanations can be categorized into three main categories: behavioral explanation, rational explanation, and collusion hypotheses.

\section{Behavioral explanation}

The behavioral explanation argues that price clustering results from psychological and behavioral preferences. Hypotheses related to behavioral explanation include attraction (Aitken et al. 1996) and psychological barrier hypotheses (Mitchell 2001). The attraction hypothesis posits that traders have a naturally-derived preference for whole numbers or specific numbers over others. Usually, the final digits with ' 0 ' and ' 5 ' are favored. Then, the psychological barrier hypothesis indicates that round numbers are easy to put up psychological barriers for investors in the financial markets. Specifically, psychological barriers in financial markets refer to numbers that prices cross less frequently than other numbers, e.g., multiples of 10 or 100.

\section{Rational explanation}

The rational explanation argues that investors' preference for round numbers is based on economic considerations. Hypotheses related to rational explanation include resolution (Ball et al. 1985) and negotiation hypotheses (Harris 1991). The price resolution hypothesis means that traders choose the whole numbers because of the uncertain value of assets. Subsequently, the negotiation hypothesis suggests that clustering at round or specific numbers effectively lowers the negotiation costs for traders. Rational explanation which stems from the hypothesis of rational man has gained population in explaining price clustering.

\section{Collusion hypothesis}

The collusion hypothesis proposed in Christie and Schultz (1994) argues that price clustering is due to implicit collusion among market dealers. In detail, Christie and Schultz (1994) implied that market makers in the NASDAQ market implicitly colluded to obtain wider bid-ask spreads, which induced the absence of odd-eighth quotes.

In addition to the above-mentioned main hypotheses, some specific factors have also found to be correlated with the price clustering phenomenon. Recent studies have focused on the trade mechanism related to price discovery. Davis et al. (2014) suggested that high-frequency trading can reduce the scale of stock price clustering on prices ending with zero or five in the NASDAQ, probably caused by psychological bias. Similarly, 
Das and Kadapakkam (2020) presented evidence that machine algorithm trading can help diminish price clustering on zero or five in the ETF market in the post-decimalization. Moreover, Baig and Sabah (2020) showed that stocks with high short-selling activity have less price clustering than those with light short-selling activity. However, other studies have considered asset-specific factors. Baig et al. (2019b) found that economic freedom in the ADR home country is negatively associated with the level of price clustering in ADR on the US exchange. Also, Baig et al. (2020) indicated a negative correlation between the reduction in the opacity of financial firms and the level of price clustering from the 2002 Sarbanes-Oxley (SOX) Act.

Regarding BTC markets, several studies have attempted to explain the price clustering of BTC/USD. The empirical results of Urquhart (2017) substantiated the negotiation hypothesis proposed by Harris (1991) that price level and volume are positively associated with price clustering in BTC/USD on round numbers. Nevertheless, Li et al. (2020) applied the psychological barrier hypothesis to account for the phenomenon of intraday BTC/USD price clustering. Besides, Baig et al. (2019a) discovered a positive correlation between the price clustering in BTC/USD and the investor sentiment indexed by Google Trends. Currently, explanations for price clustering in Bitcoin are being explored in research.

\section{Data and methodology}

\section{Data description}

Despite the numerous online crypto exchanges operating BTC/JPY transactions conducted in Japan, this study mainly focuses on the analysis of Coincheck, BtcBox, and bitFlyer for their long trading history, good liquidity, and data availability. All the three are registered online crypto exchanges providing BTC/JPY transactions under regulation. And the minimum price change is 1 JPY across the three online crypto exchanges.

The tick-by-tick data of BTC prices used in this study were obtained from bitcoincha rts where detailed historical transaction data are provided. Every single transaction record has a unix timestamp, price in fiat currency, and amount in BTC. The transactions with zero amount or prices with decimals to make up only a tiny proportion are removed. Eventually, all prices of BTC/JPY in the sample are in integers.

Table 1 reports sample information. Initially, unix timestamps of all data are converted into Greenwich Mean Time (GMT) which is nine hours behind Japan Standard Time (JST). The data collected from Coincheck and BtcBox are sampled during the

Table 1 Crypto exchanges and samples

\begin{tabular}{lllll}
\hline Exchange & Starting & Ending & Transaction & Obs/Hours \\
\hline Coincheck & $1 / 1 / 2015$ & $4 / 30 / 2020$ & $142,274,189$ & 46,064 \\
BtcBox & $1 / 1 / 2015$ & $4 / 30 / 2020$ & $27,735,549$ & 45,595 \\
bitFlyer & $8 / 1 / 2017$ & $4 / 30 / 2020$ & $45,749,657$ & 18,628 \\
\hline
\end{tabular}

This table describes a sample of each online crypto exchange. Founded in Tokyo, Coincheck, BtcBox, and bitFlyer are three registered crypto exchanges under the regulation of the Financial Services Agency of Japan. The statistics include the starting date (Starting), ending date (Ending), number of tick-by-tick transactions (Transaction), and number of hourly observations transformed from transactions (Obs/Hours). Additionally, for Coincheck, 1073 transactions spanning from March 23 to April 30, 2020 were excluded from the sample because their prices range from $170 \mathrm{JPY}$ to $510 \mathrm{JPY}$, which are much lower than those of previous and subsequent transactions 
period from January 1, 2015 to April 30, 2020, and the data obtained from bitFlyer span discretely from August 1, 2017 to April 30, 2020. Therefore, the number of tickby-tick transactions from Coincheck, BtcBox, and bitFlyer is 142,274,189, 27,735,549, and $45,749,657$, respectively. To study the intraday patterns of price clustering, all transaction data are aggregated as hourly variables, for example, price clustering degrees, volume, transaction counts, and so on. Thus, the number of final observations is $46,064,45,595$, and 18,628, respectively. According to the transaction counts and hours, it is indicated that transactions on Coincheck and bitFlyer are much more frequent than those on BtcBox on the whole.

\section{Methodology}

Subsequent to Ohta (2006), two variables were used to assess the scale of price clustering. For each transaction, the dummy variable DIGIT00 was used. If the last two digits of price are '00', one is assigned. Otherwise, zero is taken. In a specific time interval, AVG represents the simple average of DIGIT00, whereas the concentration ratio (CR) refers to the volume-weighted average of DIGIT00. As the price clustering phenomenon is easily detected, simple statistical measures, i.e., AVG and CR, are adopted instead of clustering algorithms for financial data (e.g., Kou et al. 2014; Dias et al. 2015; Musmeci et al. 2015; Li et al. 2021).

To explore the hour-of-the-day effect of price clustering in BTC/JPY, a linear model with hour dummies is applied.

$$
r=\alpha+\sum_{n=1}^{23} \beta_{n} D_{n}+\sum_{i=1}^{m} \beta_{i} x_{i}+\epsilon
$$

where $\mathrm{r}$ indicates the extent of price clustering. $D_{n}$ stands for the hour dummy variable, and $x_{i}$ refers to the control variable that is potentially associated with the extent of price clustering in BTC/JPY. Accordingly, $\alpha$ is the intercept of the regression equation, and $\beta$ is the coefficient of the variable. Also, $\epsilon$ is the error term.

To account for differences in the scales of price clustering between hour intervals, the error term $\epsilon$ is specified to be heteroscedastic across hour intervals but without cross-sectional correlation in this study. The assumption of heteroscedasticity is imposed because the scales of price clustering may not be identically distributed across hour intervals. In the presence of heteroscedasticity, the ordinary least squares (OLS) is unbiased but inefficient. Therefore, Equation 1 is estimated by the feasible generalized least squares (FGLS) because generalized least squares (GLS) is unbiased and efficient under heteroscedasticity.

In this study, the control variables are weekday dummies and variables similar to those in Harris (1991) and Ohta (2006) following the negotiation hypothesis (Harris 1991), including logMeanp, logCount, logVolsum, Rangep, and price volatility.

logMeanp is purposed to measure the effect of BTC/JPY price, which is the logarithm of the average price during the interval. A truly high price makes it inefficient to collect accurate information from prices. Thus, the coefficient of logMeanp is supposed to be positive. 
logVolsum refers to a logarithm of the total amount of BTC (Volume) at a specific interval. Aitken et al. (1996) argued that the large orders associated with informed traders would increase clustering. Urquhart (2017) applied BTC/USD from Bitstamp to discover that trading volume is positively related to price clustering. Thus, the coefficient of $\log$ Volsum is anticipated to be positive.

$\log$ Count is the logarithm of the total number of transaction times (Count) at a specific interval. As frequent transactions make it easy to identify the underlying value of assets, the coefficient of logCount is supposed to be negative.

Rangep is the range of transaction prices divided by the mean price at a specific interval, which indicates the relative level of fluctuation. As it is difficult to obtain accurate information on asset prices due to huge price changes, Rangep is supposed to be positively associated with price clustering.

Realized volatility or realized variance (RV) was utilized in this study to capture the relationship between daily volatility and price clustering. Proposed by Andersen and Bollerslev (1998), RV is commonly used as an ex-post measure of volatility in financial studies. Following (Eross et al. 2019), RV is computed using 5-min high-frequency data aggregated from tick data. Similar to Rangep, RV is supposed to be positively correlated with price clustering.

\section{Empirical results}

\section{Price clustering at numbers ending with ' 00 '}

Table 2 presents the five most frequent and five least frequent two-digit ending numbers. For all the three exchanges, the most frequent ending numbers is '00', accounting for 7.59\%, 3.13\%, and $20.01 \%$ on Coincheck, BtcBox, and bitFlyer, respectively. The prices ending with ' 99 ' rank second and are followed by those ending with '01' or ' 50 '. Furthermore, price clustering at ' 01 ' and ' 99 ' provides evidence for strategic pricing.

Table 2 Frequencies of two-digit ending numbers of BTC/JPY

\begin{tabular}{|c|c|c|c|c|c|c|c|c|c|}
\hline \multirow[b]{2}{*}{ Rank } & \multicolumn{3}{|c|}{ Coincheck } & \multicolumn{3}{|c|}{ BtcBox } & \multicolumn{3}{|c|}{ bitFlyer } \\
\hline & $\begin{array}{l}\text { Last2 } \\
\text { (1) }\end{array}$ & $\begin{array}{l}\text { Frequency } \\
\text { (2) }\end{array}$ & $\begin{array}{l}\text { Percent } \\
\text { (3) }\end{array}$ & $\begin{array}{l}\text { Last2 } \\
\text { (1) }\end{array}$ & $\begin{array}{l}\text { Frequency } \\
\text { (2) }\end{array}$ & $\begin{array}{l}\text { Percent } \\
\text { (3) }\end{array}$ & $\begin{array}{l}\text { Last2 } \\
\text { (1) }\end{array}$ & $\begin{array}{l}\text { Frequency } \\
\text { (2) }\end{array}$ & $\begin{array}{l}\text { Percent } \\
\text { (3) }\end{array}$ \\
\hline 1 & 00 & $10,805,445$ & 7.59 & 00 & 867,420 & 3.13 & 00 & $9,156,300$ & 20.01 \\
\hline 2 & 99 & $4,683,915$ & 3.29 & 99 & 324,041 & 1.17 & 99 & $1,418,603$ & 3.10 \\
\hline 3 & 01 & $4,610,442$ & 3.24 & 50 & 309,263 & 1.12 & 01 & $1,310,337$ & 2.86 \\
\hline 4 & 95 & $1,925,696$ & 1.35 & 01 & 299,767 & 1.08 & 50 & 888,294 & 1.94 \\
\hline 5 & 05 & $1,917,480$ & 1.35 & 10 & 289,909 & 1.05 & 90 & 844,680 & 1.85 \\
\hline$\cdots$ & $\cdots$ & $\cdots$ & $\cdots$ & $\cdots$ & $\cdots$ & $\cdots$ & $\cdots$ & $\cdots$ & $\cdots$ \\
\hline 96 & 73 & $1,080,751$ & 0.76 & 47 & 264,560 & 0.95 & 73 & 253,369 & 0.55 \\
\hline 97 & 72 & $1,080,038$ & 0.76 & 74 & 264,367 & 0.95 & 64 & 252,182 & 0.55 \\
\hline 98 & 63 & $1,075,818$ & 0.76 & 13 & 264,282 & 0.95 & 36 & 251,759 & 0.55 \\
\hline 99 & 37 & $1,070,714$ & 0.75 & 76 & 264,026 & 0.95 & 37 & 251,082 & 0.55 \\
\hline 100 & 67 & $1,068,406$ & 0.75 & 64 & 262,655 & 0.95 & 46 & 250,803 & 0.55 \\
\hline
\end{tabular}

This table reports the frequencies and proportions of the five most frequent and five least frequent two-digit ending numbers of each crypto exchange during each sample period. 'Last2' indicates the two-digit ending numbers; 'Frequency' denotes the count of a specific two-digit ending number observed in the sample; and 'Percent' shows the proportion of a specific two-digit ending number in percentage 
Figure 1 shows the proportions of all two-digit ending numbers. First, plot (a) shows that proportions of '00,' '01', and '99' significantly exceed those of other ending numbers on Coincheck. Second, plot (b) shows that on BtcBox, proportions of two-digit ending numbers are all around 1\%, except for ' 00 '. Further, plot (c) reveals that price clusters at round numbers ending with ' 0 ' on bitFlyer, but '00' accounts for the most. Therefore, the proportions of the two-digit ending numbers demonstrate that the BTC/JPY prices from the three online exchanges cluster more at numbers ending with '00' over others. Still, the scales of price clustering vary with exchanges.

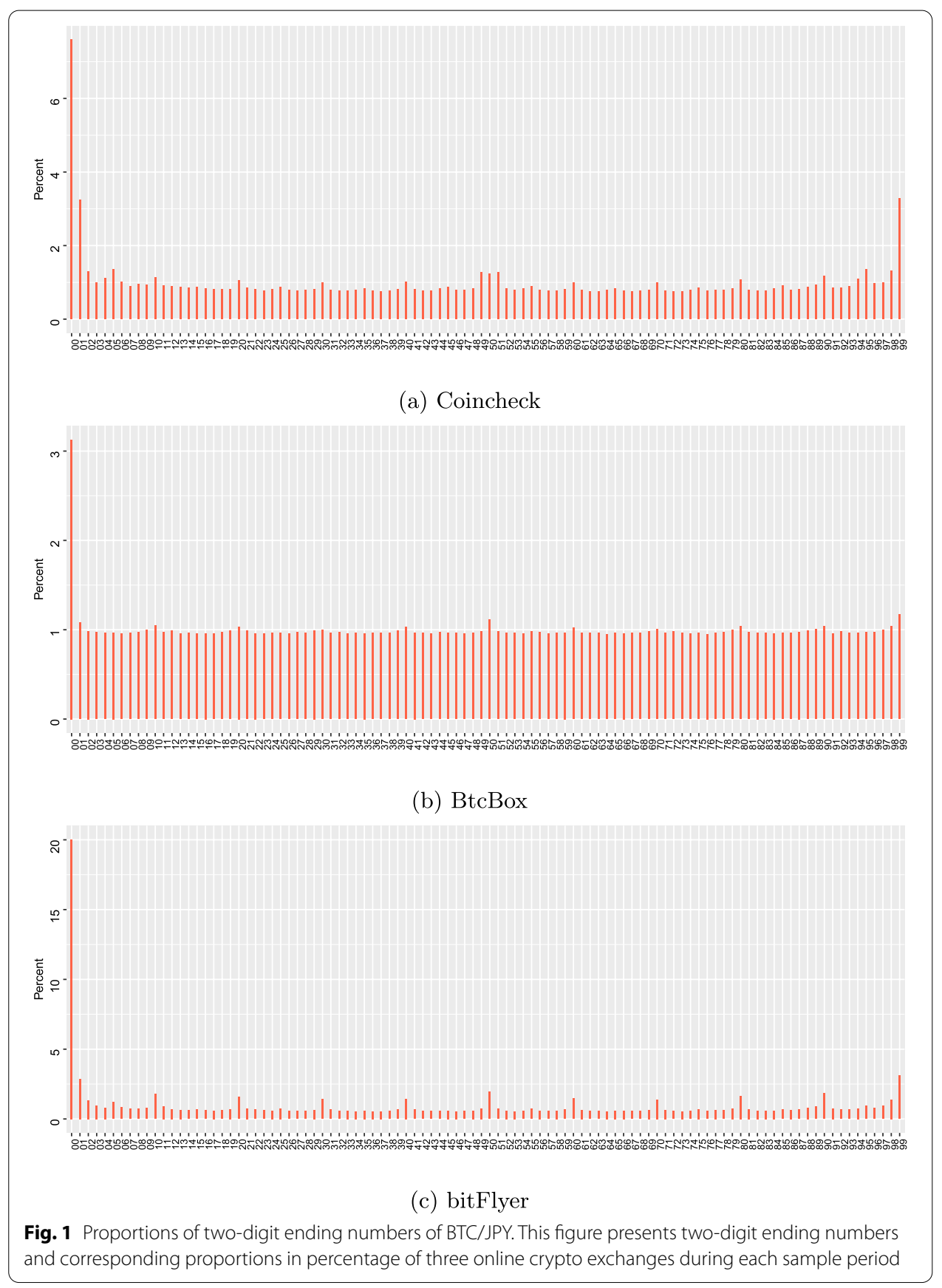




\section{Price clustering at continuous transactions}

Figure 2 illustrates the hourly AVG and CR on a daily basis with scatter points. The legend on the right side of each plot accounts for the correlation between the colors of the points and the corresponding hour intervals in the plots. To enhance readability, hours in GMT and local time JST are both given in the legend. For instance, GMT00_ JST09 means hour00 in GMT and hour09 in JST, as GMT is nine hours behind JST. First, plot (a) reveals that the scatters in both plots (AVG and CR) exhibit a layered phenomenon on Coincheck from 2017, suggesting that the extent of price clustering varies considerably over time throughout a trading day since 2017 , and price clustering is reduced in the early morning. Initially, as the hourly volume in BTC was relatively low and transaction counts were small (see "Appendix"), the scale of hourly price clustering on Coincheck fluctuated significantly. Then, with growing acceptance by the massive (see Hairudin et al. 2020), both hourly volume and transaction counts increased significantly since the Bitcoin bubble in 2017. Accordingly, hourly price clustering appeared to be relatively stable. Second, plot (b) shows no visible intraday pattern in the price clustering on BtcBox, but the extent of price clustering shows a more significant fluctuation. This is probably because transactions on BtcBox were not as active as those on Coincheck and bitFlyer based on hourly transaction counts. Third, plot (c) indicates a remarkable intraday pattern in the price clustering of BTC/ JPY on bitFlyer during the sample period, which starts from August 1, 2017. To conclude, the intraday pattern of price clustering in BTC/JPY varies with market conditions and online crypto exchanges.

Figure 3 presents estimates with 95\% confidence intervals from the regression results of hourly AVG/CR on 23 hour dummies except for JST09, using the data collected from Coincheck, BtcBox, and bitFlyer. Observably, estimates tend to decline from JST23 to JST04 and recover from JST05 to JST08. Alternatively, the scale of price clustering is prone to be lower during the interval from JST00 to JST07 compared with those in previous hour intervals across the three online crypto exchanges.

Table 3 details the regression results of hourly AVG/CR on hour dummies for the three online crypto exchanges. Generally speaking, the extent of price clustering, as indexed by both AVG and CR, tends to be lower from JST02 to JST07. Initially, the intercept in each regression represents the extent of price clustering at JST09, corresponding to the interval lasting from 9:00 to 9:59 JST. The intercepts in Table 3 show that the extent of price clustering is statistically significant from zero at the $1 \%$ level and obviously exceeds 1\% from 9:00 to 9:59 JST. Furthermore, the coefficients of other variables are the differences in the extent of price clustering between other hour intervals and JST09. For Coincheck, the coefficients from JST02 to JST07 are negative and statistically different from zero at the 5\% significance level, suggesting that the extent of price clustering is significantly lower from 2:00 to 7:59 JST in the early morning. For BtcBox, AVG is substantially higher from JST18 to JST00, but is significantly lower from JST03 to JST05. However, for the CR of BtcBox, it exhibits no similar intraday pattern. For bitFlyer, AVG and CR are considerably lower from JST00 to JST08. Furthermore, the estimates for CR of Coincheck and bitFlyer during JST02 to JST07 are notably lower than those for AVG, suggesting that the proportion of transaction amounts with the prices clustering at ' 00 ' is lower in the morning across Japan. 

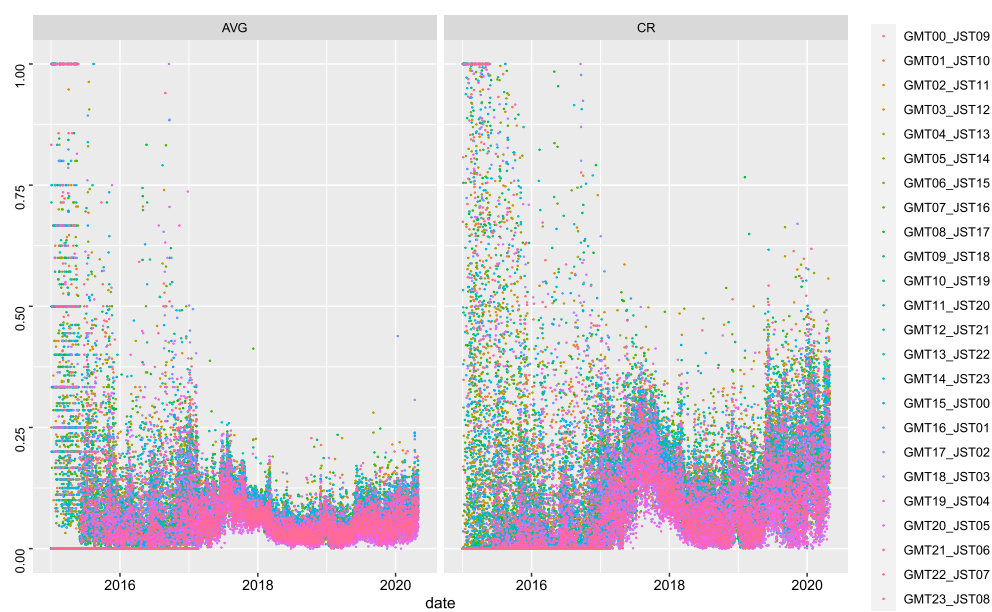

(a) Coincheck
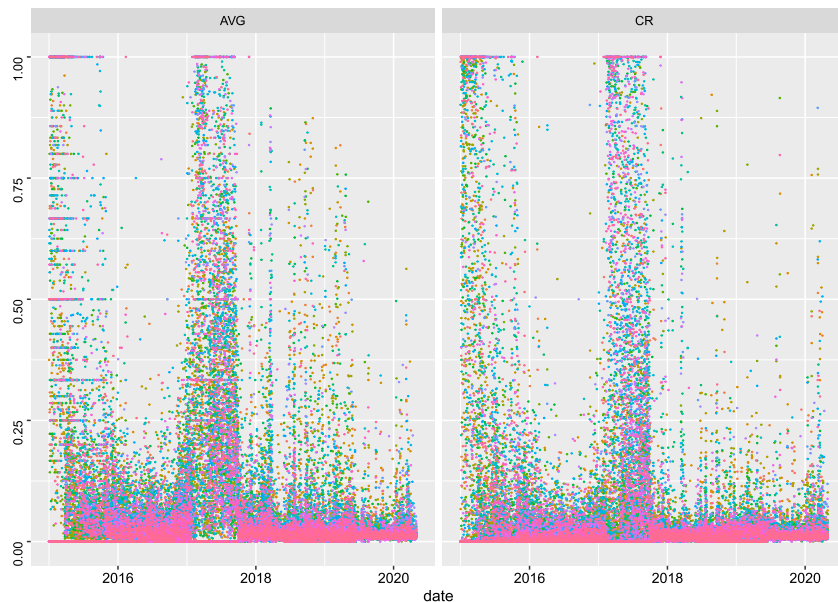

(b) BtcBox
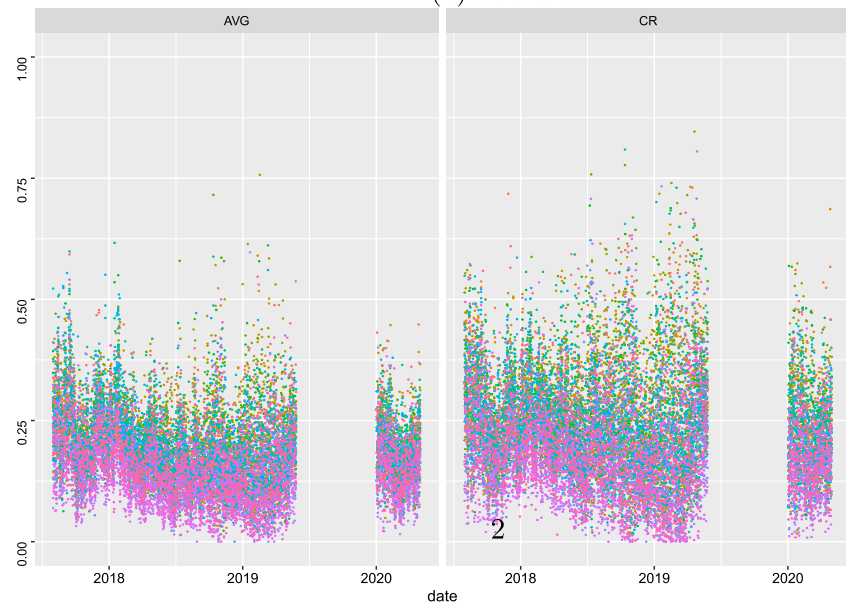

GMTO0 JSTO9

GMT01_JST10

GMTO2_JST11

GMTO3_JST12

GMT04_SST13

GMT05_JST14

GMT06_JST15

GMT07_JST16

GMT08_JST17

GMTO9_JST18

GMT10_JST19

GMT11_JST20

GMT12_JST21

GMT13 JST22

GMT14_JST23

GMT15_JSTOO

GMT16_JST01

GMT17_JSTO2

GMT18_JSTO3

GMT19_JSTO4

GMT20_JSTOS

GMT21_JSTO6

GMT22_JSTO7

GMT23_JST08

(c) bitFlyer

Fig. 2 The extent of hourly price clustering of BTC/JPY. This figure presents hourly AVG and CR of three online crypto exchanges on a daily basis during each sample period 
Table 3 The scale of price clustering on hour dummies

\begin{tabular}{|c|c|c|c|c|c|c|}
\hline & \multicolumn{2}{|l|}{ Coincheck } & \multicolumn{2}{|l|}{ BtcBox } & \multicolumn{2}{|l|}{ bitFlyer } \\
\hline & AVG & CR & AVG & CR & AVG & CR \\
\hline & (1) & (2) & (1) & (2) & (1) & $(2)$ \\
\hline \multirow[t]{2}{*}{ Intercept } & $0.0744^{* * *}$ & $0.1208^{* * *}$ & $0.0900^{* * *}$ & $0.0560^{* * *}$ & $0.1913^{* * *}$ & $0.2437^{* * *}$ \\
\hline & $(0.0021)$ & $(0.0029)$ & $(0.0038)$ & $(0.0033)$ & $(0.0030)$ & $(0.0039)$ \\
\hline \multirow[t]{2}{*}{ GMT01_JST10 } & 0.0004 & 0.0027 & 0.0074 & 0.0076 & $0.0108^{*}$ & $0.0211^{* * *}$ \\
\hline & $(0.0030)$ & $(0.0041)$ & $(0.0055)$ & $(0.0050)$ & $(0.0043)$ & $(0.0059)$ \\
\hline \multirow[t]{2}{*}{ GMT02_JST11 } & -0.0025 & -0.0030 & 0.0067 & $0.0100^{*}$ & 0.0067 & $0.0116^{*}$ \\
\hline & $(0.0030)$ & $(0.0041)$ & $(0.0055)$ & $(0.0050)$ & $(0.0042)$ & $(0.0057)$ \\
\hline \multirow[t]{2}{*}{ GMT03_JST12 } & 0.0025 & 0.0013 & 0.0080 & $0.0114^{*}$ & $0.0116^{* *}$ & $0.0188^{* *}$ \\
\hline & $(0.0031)$ & $(0.0041)$ & $(0.0055)$ & $(0.0050)$ & $(0.0043)$ & $(0.0058)$ \\
\hline \multirow[t]{2}{*}{ GMT04_JST13 } & 0.0004 & -0.0001 & 0.0082 & $0.0138^{* *}$ & $0.0111^{* *}$ & $0.0224^{* * *}$ \\
\hline & $(0.0031)$ & $(0.0042)$ & $(0.0056)$ & $(0.0052)$ & $(0.0042)$ & $(0.0057)$ \\
\hline \multirow[t]{2}{*}{ GMT05_JST14 } & -0.0003 & 0.0036 & 0.0074 & $0.0135^{* *}$ & 0.0060 & 0.0085 \\
\hline & $(0.0030)$ & $(0.0042)$ & $(0.0056)$ & $(0.0052)$ & $(0.0044)$ & $(0.0058)$ \\
\hline \multirow[t]{2}{*}{ GMT06_JST15 } & 0.0021 & 0.0040 & 0.0017 & 0.0060 & $0.0086^{*}$ & $0.0155^{* *}$ \\
\hline & $(0.0031)$ & $(0.0042)$ & $(0.0055)$ & $(0.0049)$ & $(0.0044)$ & $(0.0059)$ \\
\hline \multirow[t]{2}{*}{ GMT07_JST16 } & 0.0022 & 0.0050 & 0.0038 & $0.0116^{*}$ & 0.0086 & $0.0139^{*}$ \\
\hline & $(0.0031)$ & $(0.0042)$ & $(0.0056)$ & $(0.0052)$ & $(0.0045)$ & $(0.0060)$ \\
\hline \multirow[t]{2}{*}{ GMT08_JST17 } & 0.0023 & 0.0067 & 0.0048 & $0.0155^{* *}$ & 0.0037 & 0.0086 \\
\hline & $(0.0031)$ & $(0.0042)$ & $(0.0056)$ & $(0.0053)$ & $(0.0042)$ & $(0.0056)$ \\
\hline \multirow[t]{2}{*}{ GMT09_JST18 } & 0.0015 & 0.0069 & $0.0119^{*}$ & $0.0252^{* * *}$ & 0.0025 & 0.0043 \\
\hline & $(0.0032)$ & $(0.0043)$ & $(0.0059)$ & $(0.0056)$ & $(0.0042)$ & $(0.0057)$ \\
\hline \multirow[t]{2}{*}{ GMT10_JST19 } & -0.0014 & 0.0012 & $0.0145^{*}$ & $0.0284^{* * *}$ & -0.0012 & -0.0062 \\
\hline & $(0.0029)$ & $(0.0040)$ & $(0.0059)$ & $(0.0057)$ & $(0.0042)$ & $(0.0055)$ \\
\hline \multirow[t]{2}{*}{ GMT11_JST20 } & 0.0035 & 0.0078 & $0.0130^{*}$ & $0.0290^{* * *}$ & 0.0007 & -0.0053 \\
\hline & $(0.0031)$ & $(0.0043)$ & $(0.0060)$ & $(0.0058)$ & $(0.0042)$ & $(0.0055)$ \\
\hline \multirow[t]{2}{*}{ GMT12_JST21 } & 0.0037 & 0.0047 & $0.0181^{* *}$ & $0.0345^{* * *}$ & 0.0031 & -0.0051 \\
\hline & $(0.0030)$ & $(0.0041)$ & $(0.0060)$ & $(0.0059)$ & $(0.0042)$ & $(0.0054)$ \\
\hline \multirow[t]{2}{*}{ GMT13_JST22 } & 0.0045 & 0.0078 & $0.0218^{* * *}$ & $0.0392^{* * *}$ & 0.0081 & -0.0008 \\
\hline & $(0.0030)$ & $(0.0041)$ & $(0.0061)$ & $(0.0060)$ & $(0.0043)$ & $(0.0054)$ \\
\hline \multirow[t]{2}{*}{ GMT14_JST23 } & 0.0040 & 0.0064 & $0.0203^{* *}$ & $0.0365^{* * *}$ & -0.0004 & -0.0094 \\
\hline & $(0.0031)$ & $(0.0042)$ & $(0.0062)$ & $(0.0060)$ & $(0.0043)$ & $(0.0054)$ \\
\hline \multirow[t]{2}{*}{ GMT15_JST00 } & -0.0021 & -0.0029 & $0.0180^{* *}$ & $0.0344^{* * *}$ & $-0.0140^{* *}$ & $-0.0248^{* * *}$ \\
\hline & $(0.0029)$ & $(0.0040)$ & $(0.0062)$ & $(0.0060)$ & $(0.0043)$ & $(0.0055)$ \\
\hline \multirow[t]{2}{*}{ GMT16_JST01 } & -0.0039 & -0.0056 & 0.0077 & $0.0288^{* * *}$ & $-0.0329^{* * *}$ & $-0.0426^{* * *}$ \\
\hline & $(0.0031)$ & $(0.0042)$ & $(0.0061)$ & $(0.0060)$ & $(0.0041)$ & $(0.0054)$ \\
\hline \multirow[t]{2}{*}{ GMT17_JST02 } & $-0.0117^{* * *}$ & $-0.0204^{* * *}$ & -0.0054 & $0.0164^{* *}$ & $-0.0533^{* * *}$ & $-0.0640^{* * *}$ \\
\hline & $(0.0031)$ & $(0.0041)$ & $(0.0060)$ & $(0.0057)$ & $(0.0040)$ & $(0.0055)$ \\
\hline GMT18_JST03 & $-0.0155^{* * *}$ & $-0.0277^{* * *}$ & $-0.0152^{* *}$ & 0.0074 & $-0.0641^{* * *}$ & $-0.0803^{* * *}$ \\
\hline & $(0.0033)$ & $(0.0042)$ & $(0.0058)$ & $(0.0055)$ & $(0.0042)$ & $(0.0058)$ \\
\hline GMT19_JST04 & $-0.0213^{* * *}$ & $-0.0376^{* * *}$ & $-0.0208^{* * *}$ & 0.0037 & $-0.0614^{* * *}$ & $-0.0840^{* * *}$ \\
\hline & $(0.0031)$ & $(0.0040)$ & $(0.0057)$ & $(0.0055)$ & $(0.0042)$ & $(0.0056)$ \\
\hline GMT20_JST05 & $-0.0218^{* * *}$ & $-0.0372^{* * *}$ & $-0.0168^{* *}$ & 0.0102 & $-0.0602^{* * *}$ & $-0.0807^{* * *}$ \\
\hline & $(0.0031)$ & $(0.0039)$ & $(0.0057)$ & $(0.0055)$ & $(0.0040)$ & $(0.0054)$ \\
\hline GMT21_JST06 & $-0.0151^{* * *}$ & $-0.0198^{* * *}$ & -0.0054 & $0.0191^{* * *}$ & $-0.0391^{* * *}$ & $-0.0563^{* * *}$ \\
\hline & $(0.0031)$ & $(0.0042)$ & $(0.0059)$ & $(0.0057)$ & $(0.0041)$ & $(0.0055)$ \\
\hline GMT22_JST07 & $-0.0080^{*}$ & $-0.0146^{* * *}$ & -0.0026 & $0.0202^{* * *}$ & $-0.0184^{* * *}$ & $-0.0311^{* * *}$ \\
\hline & $(0.0033)$ & $(0.0042)$ & $(0.0059)$ & $(0.0057)$ & $(0.0041)$ & $(0.0056)$ \\
\hline
\end{tabular}


Table 3 (continued)

\begin{tabular}{|c|c|c|c|c|c|c|}
\hline & \multicolumn{2}{|c|}{ Coincheck } & \multicolumn{2}{|l|}{ BtcBox } & \multicolumn{2}{|l|}{ bitFlyer } \\
\hline & AVG & CR & AVG & CR & AVG & CR \\
\hline & (1) & (2) & (1) & (2) & (1) & (2) \\
\hline \multirow[t]{2}{*}{ GMT23_JST08 } & -0.0053 & -0.0053 & 0.0049 & $0.0223^{* * *}$ & $-0.0099^{*}$ & $-0.0207^{* * *}$ \\
\hline & $(0.0031)$ & $(0.0042)$ & $(0.0057)$ & $(0.0056)$ & $(0.0042)$ & $(0.0056)$ \\
\hline$N$ & 46,064 & 46,064 & 45,595 & 45,595 & 15,746 & 15,746 \\
\hline Log likelihood & $41,113.46$ & $28,458.96$ & $11,042.28$ & $11,357.60$ & $18,071.69$ & $13,578.86$ \\
\hline Wald Chi2(23) & $276.13^{* * *}$ & $541.91^{* * *}$ & $147.34^{* * *}$ & $150.15^{* * *}$ & $1774.90^{* * *}$ & $1678.91^{* * *}$ \\
\hline
\end{tabular}

This table reports the regression results of the hourly price clustering degree on 23 hour dummies. AVG represents the simple average of DIGIT00, while CR (concentration ratio) refers to the volume-weighted average of DIGIT00. Standard errors are reported in parentheses. The number of observations (N), log likelihood, and Chi squared (Chi2) are also reported. Data from bitFlyer in regressions span continuously from August 1, 2017 to May 26, 2019, whereas data from Coincheck and BtcBox are sampled from January 1, 2015 to April 30, 2020.*****, and * denote statistical significance at the $0.1 \%, 1 \%$, and $5 \%$ levels, respectively

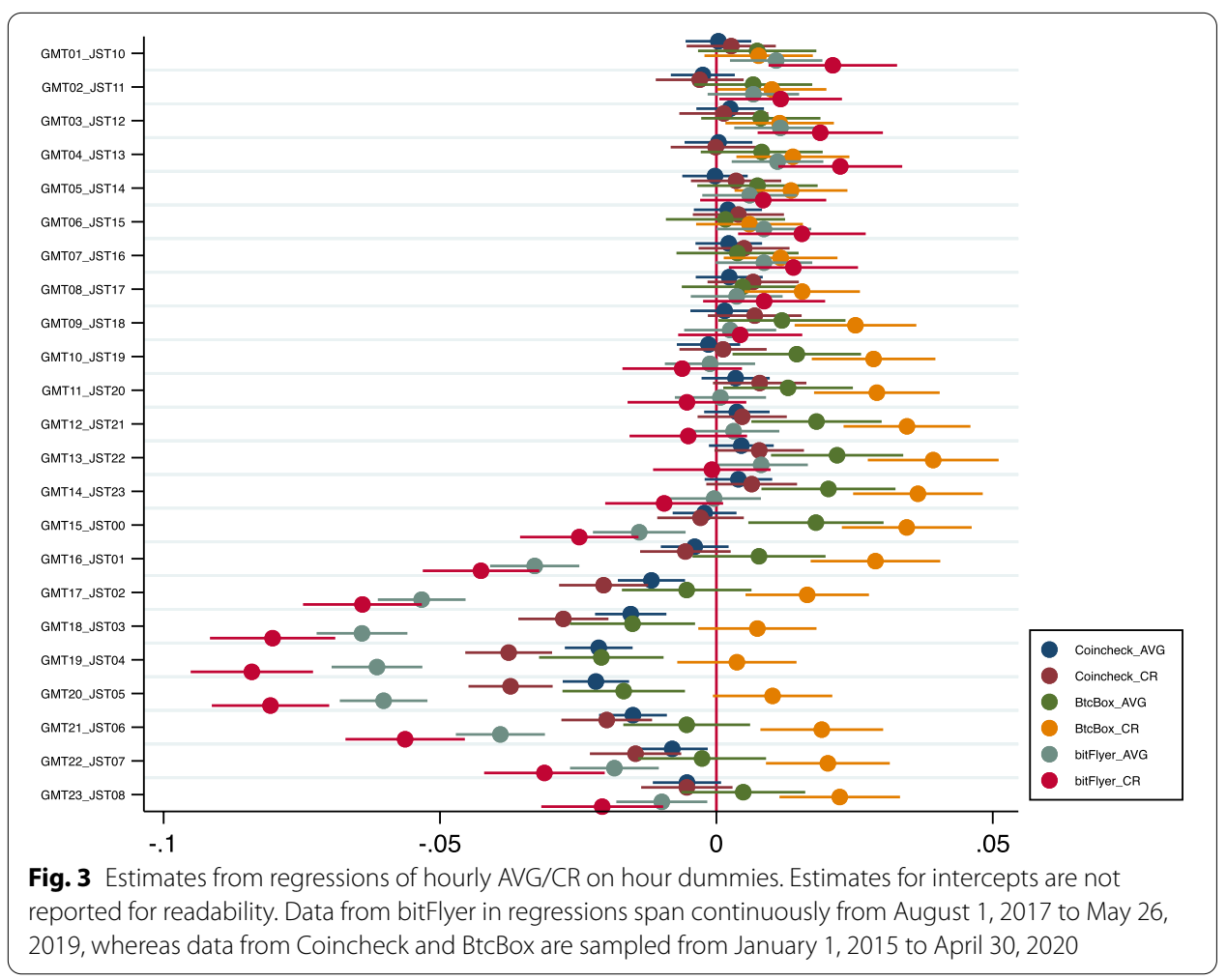

Despite no opening or closing in online crypto exchanges like traditional asset markets, the prominent intraday patterns of price clustering remain available with data from Coincheck and bitFlyer.

\section{Day-of-the-week effect on price clustering}

Figure 4 presents estimates with $95 \%$ confidence intervals from regression results on the hour and week dummies to examine the existence of the day-of-the-week effect on price clustering. The day-of-the-week effect on BTC price clustering was first documented by 


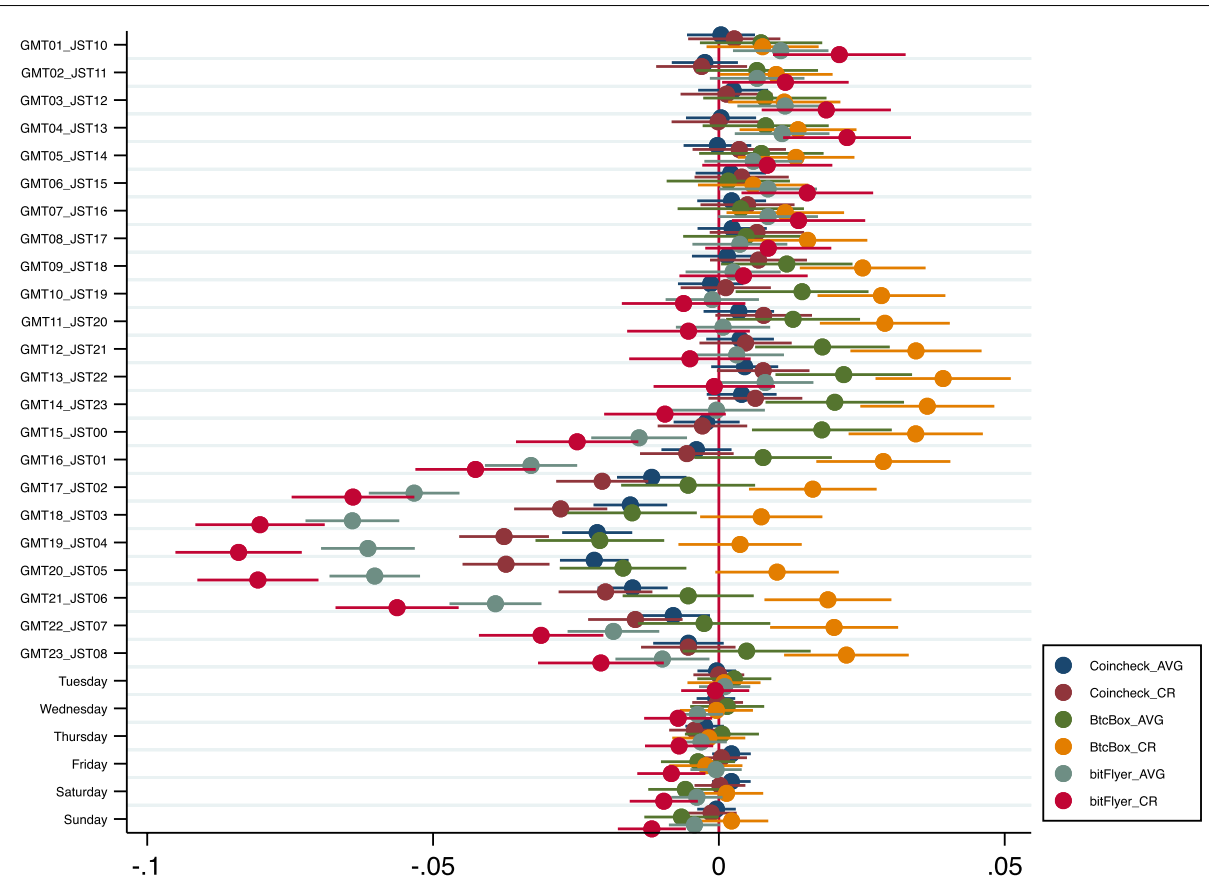

Fig. 4 Estimates from regressions of hourly AVG/CR on the hour and weekday dummies. Estimates for intercepts are not reported for readability. Data from bitFlyer in regressions span continuously from August 1, 2017 to May 26, 2019, whereas data from Coincheck and BtcBox are sampled from January 1, 2015 to April 30,2020

Mbanga (2019). Specifically, Mbanga (2019) found that the degree of BTC/USD price clustering at whole numbers is higher on Fridays and lower on Mondays using the daily closing price data of Bitstamps. However, empirical results in Fig. 4 show that compared to price clustering on Monday, the price clustering degrees indexed by AVG of BtcBox and CR of bitFlyer are the lowest on Sunday. In summary, except for AVG of BtcBox and CR of bitFlyer, there is no apparent day-of-the-week effect on price clustering in BTC/ JPY across the three online crypto exchanges when hour dummies are incorporated.

\section{Intraday patterns in price clustering with negotiation hypothesis}

Figure 5 presents estimates with 95\% confidence intervals from regression results of hourly AVG/CR on 23 hour dummies with control variables drawn from the negotiation hypothesis (Harris 1991; Ohta 2006; Urquhart 2017). Also, estimates for intercepts and control variables based on the negotiation hypothesis, including logMeanp, logCount, logVolsum, Rangep, and RV are not reported for readability. Observably, estimates for dummies exhibit a similar trend as those in Fig. 3, suggesting that the intraday patterns in price clustering are still available after incorporating control variables drawn from the negotiation hypothesis.

Table 4 details the regression results of models incorporating control variables. Observably, the extent of price clustering across the three online crypto exchanges remains lower from JST02 to JST07 on the whole. After adding control variables, the coefficients for CR of BtcBox from JST02 to JST07 are negative, while the coefficients for JST03, JST04, and JST05 show statistical significance from zero at the 5\% level. 


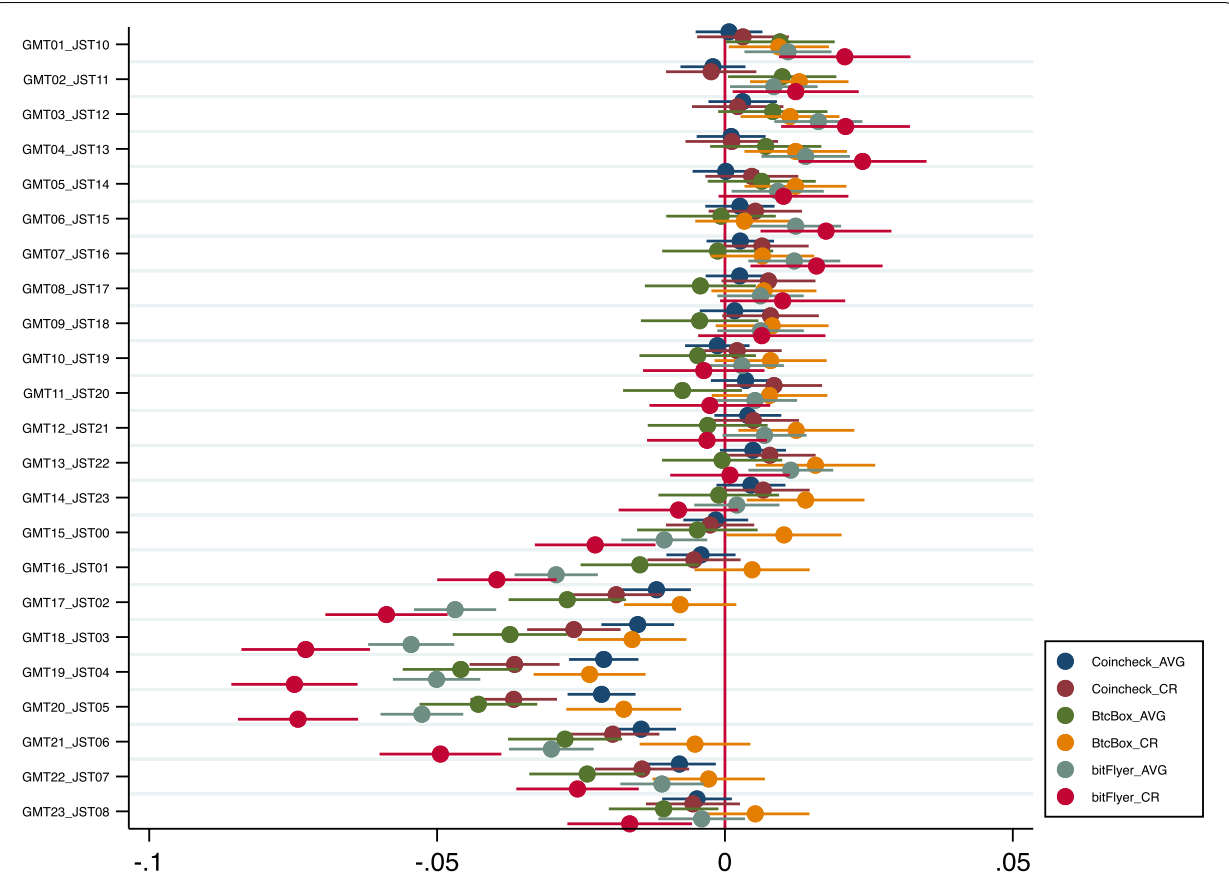

Fig. 5 Estimates from regressions of hourly AVG/CR on hour dummies with control variables. Only estimates for hourly dummies are presented, whereas estimates for intercepts and control variables (logMeanp, logCount, logVolsum, Rangep, and RV) are not reported for readability. Data from bitFlyer in regressions span continuously from August 1, 2017 to May 26, 2019, whereas data from Coincheck and BtcBox are sampled from January 1, 2015 to April 30, 2020

Meanwhile, all of the coefficients from JST02 to JST07 are negative, with most showing a statistical significance from zero at the $1 \%$ level. Therefore, the phenomenon of lower price clustering from 2:00 to 7:59 JST is stable, which can not be accounted for using the negotiation hypothesis.

Table 5 indicates the regression results for hourly transaction counts (Count) exceeding 1,000 to eliminate the effect of a small number of transactions during hour intervals. According to the regression results, the coefficients from JST02 to JST07 are invariably negative, and most coefficients show a statistical difference from zero at the $5 \%$ level. For BtcBox, the low price clustering indexed by CR is apparent from JST03 to JST08 when transaction times exceed 1,000. Table 5 demonstrates that the differences in the extent of price clustering between the interval of 2:00 to 7:59 JST and other trading times remain when transactions are conducted frequently.

In addition, the signs of coefficients of the control variables based on the negotiation hypothesis in Tables 4 and 5 are not exactly as expected. This is because the data used in this study comprises time series from each exchange that cannot reveal a common trend as in previous studies (Harris 1991; Aitken et al. 1996; Ohta 2006), which used panel data.

\section{Robustness check}

Although the differences in the scales of price clustering between other hour intervals and JST09 have been demonstrated by using the regression method, pairwise 
Table 4 The scale of price clustering on hour dummies with control variables

\begin{tabular}{|c|c|c|c|c|c|c|}
\hline & \multicolumn{2}{|l|}{ Coincheck } & \multicolumn{2}{|l|}{ BtcBox } & \multicolumn{2}{|l|}{ bitFlyer } \\
\hline & $\begin{array}{l}\text { AVG } \\
\text { (1) }\end{array}$ & $\begin{array}{l}\mathrm{CR} \\
(2)\end{array}$ & $\begin{array}{l}\text { AVG } \\
\text { (1) }\end{array}$ & $\begin{array}{l}\mathrm{CR} \\
\text { (2) }\end{array}$ & $\begin{array}{l}\text { AVG } \\
\text { (1) }\end{array}$ & $\begin{array}{l}\text { CR } \\
\text { (2) }\end{array}$ \\
\hline Intercept & $\begin{array}{l}0.1353^{* * *} \\
(0.0091)\end{array}$ & $\begin{array}{l}0.0370^{* *} \\
(0.0120)\end{array}$ & $\begin{array}{l}0.2334^{* * *} \\
(0.0100)\end{array}$ & $\begin{array}{l}0.3631^{* * *} \\
(0.0097)\end{array}$ & $\begin{array}{l}-0.3990^{* * *} \\
(0.0224)\end{array}$ & $\begin{array}{l}-0.2459^{* * *} \\
(0.0323)\end{array}$ \\
\hline GMT01_JST10 & $\begin{array}{l}0.0007 \\
(0.0030)\end{array}$ & $\begin{array}{l}0.0031 \\
(0.0041)\end{array}$ & $\begin{array}{l}0.0096^{*} \\
(0.0048)\end{array}$ & $\begin{array}{l}0.0094^{*} \\
(0.0044)\end{array}$ & $\begin{array}{l}0.0109^{* *} \\
(0.0039)\end{array}$ & $\begin{array}{l}0.0208^{* * *} \\
(0.0058)\end{array}$ \\
\hline GMT02_JST11 & $\begin{array}{l}-0.0021 \\
(0.0029)\end{array}$ & $\begin{array}{l}-0.0024 \\
(0.0040)\end{array}$ & $\begin{array}{l}0.0100^{*} \\
(0.0048)\end{array}$ & $\begin{array}{l}0.0129^{* *} \\
(0.0044)\end{array}$ & $\begin{array}{l}0.0085^{*} \\
(0.0039)\end{array}$ & $\begin{array}{l}0.0123^{*} \\
(0.0056)\end{array}$ \\
\hline GMT03_JST12 & $\begin{array}{l}0.0031 \\
(0.0030)\end{array}$ & $\begin{array}{l}0.0022 \\
(0.0040)\end{array}$ & $\begin{array}{l}0.0083 \\
(0.0048)\end{array}$ & $\begin{array}{l}0.0113^{* *} \\
(0.0044)\end{array}$ & $\begin{array}{l}0.0162^{* * *} \\
(0.0039)\end{array}$ & $\begin{array}{l}0.0210^{* * *} \\
(0.0057)\end{array}$ \\
\hline GMT04_JST13 & $\begin{array}{l}0.0011 \\
(0.0031)\end{array}$ & $\begin{array}{l}0.0012 \\
(0.0041)\end{array}$ & $\begin{array}{l}0.0071 \\
(0.0049)\end{array}$ & $\begin{array}{l}0.0123^{* *} \\
(0.0045)\end{array}$ & $\begin{array}{l}0.0140^{* * *} \\
(0.0039)\end{array}$ & $\begin{array}{l}0.0239^{* * *} \\
(0.0057)\end{array}$ \\
\hline GMT05_JST14 & $\begin{array}{l}0.0001 \\
(0.0029)\end{array}$ & $\begin{array}{l}0.0047 \\
(0.0041)\end{array}$ & $\begin{array}{l}0.0064 \\
(0.0048)\end{array}$ & $\begin{array}{l}0.0122^{* *} \\
(0.0045)\end{array}$ & $\begin{array}{l}0.0092^{*} \\
(0.0041)\end{array}$ & $\begin{array}{l}0.0102 \\
(0.0058)\end{array}$ \\
\hline GMT06_JST15 & $\begin{array}{l}0.0026 \\
(0.0031)\end{array}$ & $\begin{array}{l}0.0053 \\
(0.0041)\end{array}$ & $\begin{array}{c}-0.0007 \\
(0.0049)\end{array}$ & $\begin{array}{l}0.0034 \\
(0.0043)\end{array}$ & $\begin{array}{l}0.0123^{* *} \\
(0.0040)\end{array}$ & $\begin{array}{l}0.0176^{* *} \\
(0.0058)\end{array}$ \\
\hline GMT07_JST16 & $\begin{array}{l}0.0027 \\
(0.0030)\end{array}$ & $\begin{array}{l}0.0064 \\
(0.0041)\end{array}$ & $\begin{array}{l}-0.0013 \\
(0.0049)\end{array}$ & $\begin{array}{l}0.0065 \\
(0.0046)\end{array}$ & $\begin{array}{l}0.0120^{* *} \\
(0.0041)\end{array}$ & $\begin{array}{l}0.0159^{* *} \\
(0.0059)\end{array}$ \\
\hline GMT08_JST17 & $\begin{array}{l}0.0026 \\
(0.0030)\end{array}$ & $\begin{array}{l}0.0076 \\
(0.0042)\end{array}$ & $\begin{array}{l}-0.0043 \\
(0.0049)\end{array}$ & $\begin{array}{l}0.0068 \\
(0.0047)\end{array}$ & $\begin{array}{l}0.0062 \\
(0.0038)\end{array}$ & $\begin{array}{l}0.0100 \\
(0.0055)\end{array}$ \\
\hline GMT09_JST18 & $\begin{array}{l}0.0017 \\
(0.0031)\end{array}$ & $\begin{array}{l}0.0079 \\
(0.0043)\end{array}$ & $\begin{array}{l}-0.0044 \\
(0.0052)\end{array}$ & $\begin{array}{l}0.0082 \\
(0.0050)\end{array}$ & $\begin{array}{l}0.0062 \\
(0.0038)\end{array}$ & $\begin{array}{l}0.0064 \\
(0.0056)\end{array}$ \\
\hline GMT10_JST19 & $\begin{array}{l}-0.0013 \\
(0.0029)\end{array}$ & $\begin{array}{l}0.0021 \\
(0.0040)\end{array}$ & $\begin{array}{l}-0.0047 \\
(0.0052)\end{array}$ & $\begin{array}{l}0.0079 \\
(0.0050)\end{array}$ & $\begin{array}{l}0.0029 \\
(0.0037)\end{array}$ & $\begin{array}{l}-0.0037 \\
(0.0054)\end{array}$ \\
\hline GMT11_JST20 & $\begin{array}{l}0.0036 \\
(0.0031)\end{array}$ & $\begin{array}{l}0.0085^{*} \\
(0.0043)\end{array}$ & $\begin{array}{l}-0.0074 \\
(0.0053)\end{array}$ & $\begin{array}{l}0.0077 \\
(0.0051)\end{array}$ & $\begin{array}{l}0.0052 \\
(0.0037)\end{array}$ & $\begin{array}{l}-0.0026 \\
(0.0054)\end{array}$ \\
\hline GMT12_JST21 & $\begin{array}{l}0.0040 \\
(0.0030)\end{array}$ & $\begin{array}{l}0.0049 \\
(0.0040)\end{array}$ & $\begin{array}{l}-0.0030 \\
(0.0053)\end{array}$ & $\begin{array}{l}0.0124^{*} \\
(0.0051)\end{array}$ & $\begin{array}{l}0.0069 \\
(0.0037)\end{array}$ & $\begin{array}{l}-0.0031 \\
(0.0053)\end{array}$ \\
\hline GMT13_JST22 & $\begin{array}{l}0.0049 \\
(0.0029)\end{array}$ & $\begin{array}{l}0.0078 \\
(0.0041)\end{array}$ & $\begin{array}{l}-0.0005 \\
(0.0053)\end{array}$ & $\begin{array}{l}0.0157^{* *} \\
(0.0053)\end{array}$ & $\begin{array}{l}0.0114^{* *} \\
(0.0038)\end{array}$ & $\begin{array}{l}0.0009 \\
(0.0053)\end{array}$ \\
\hline GMT14_JST23 & $\begin{array}{l}0.0045 \\
(0.0031)\end{array}$ & $\begin{array}{l}0.0067 \\
(0.0041)\end{array}$ & $\begin{array}{l}-0.0011 \\
(0.0053)\end{array}$ & $\begin{array}{l}0.0140^{* *} \\
(0.0052)\end{array}$ & $\begin{array}{l}0.0021 \\
(0.0038)\end{array}$ & $\begin{array}{l}-0.0081 \\
(0.0053)\end{array}$ \\
\hline GMT15_JST00 & $\begin{array}{l}-0.0016 \\
(0.0029)\end{array}$ & $\begin{array}{l}-0.0026 \\
(0.0039)\end{array}$ & $\begin{array}{l}-0.0048 \\
(0.0053)\end{array}$ & $\begin{array}{l}0.0103^{*} \\
(0.0051)\end{array}$ & $\begin{array}{l}-0.0105^{* *} \\
(0.0038)\end{array}$ & $\begin{array}{l}-0.0225^{* * *} \\
(0.0053)\end{array}$ \\
\hline GMT16_JST01 & $\begin{array}{l}-0.0042 \\
(0.0031)\end{array}$ & $\begin{array}{l}-0.0054 \\
(0.0041)\end{array}$ & $\begin{array}{l}-0.0148^{* *} \\
(0.0053)\end{array}$ & $\begin{array}{l}0.0047 \\
(0.0051)\end{array}$ & $\begin{array}{l}-0.0293^{* * *} \\
(0.0037)\end{array}$ & $\begin{array}{l}-0.0396^{* * *} \\
(0.0053)\end{array}$ \\
\hline GMT17_JST02 & $\begin{array}{l}-0.0119^{* * *} \\
(0.0030)\end{array}$ & $\begin{array}{l}-0.0189^{* * *} \\
(0.0041)\end{array}$ & $\begin{array}{l}-0.0274^{* * *} \\
(0.0052)\end{array}$ & $\begin{array}{l}-0.0078 \\
(0.0050)\end{array}$ & $\begin{array}{l}-0.0469^{* * *} \\
(0.0036)\end{array}$ & $\begin{array}{l}-0.0588^{* * *} \\
(0.0054)\end{array}$ \\
\hline GMT18_JST03 & $\begin{array}{l}-0.0151^{* * *} \\
(0.0032)\end{array}$ & $\begin{array}{l}-0.0262^{* * *} \\
(0.0041)\end{array}$ & $\begin{array}{l}-0.0373^{* * *} \\
(0.0051)\end{array}$ & $\begin{array}{l}-0.0161^{* * *} \\
(0.0048)\end{array}$ & $\begin{array}{l}-0.0545^{* * *} \\
(0.0038)\end{array}$ & $\begin{array}{l}-0.0728^{* * *} \\
(0.0057)\end{array}$ \\
\hline GMT19_JST04 & $\begin{array}{l}-0.0210^{* * *} \\
(0.0031)\end{array}$ & $\begin{array}{l}-0.0365^{* * *} \\
(0.0040)\end{array}$ & $\begin{array}{l}-0.0459^{* * *} \\
(0.0051)\end{array}$ & $\begin{array}{l}-0.0235^{* * *} \\
(0.0050)\end{array}$ & $\begin{array}{l}-0.0501^{* * *} \\
(0.0039)\end{array}$ & $\begin{array}{l}-0.0748^{* * *} \\
(0.0056)\end{array}$ \\
\hline GMT20_JST05 & $\begin{array}{l}-0.0214^{* * *} \\
(0.0030)\end{array}$ & $\begin{array}{l}-0.0367^{* * *} \\
(0.0038)\end{array}$ & $\begin{array}{l}-0.0428^{* * *} \\
(0.0052)\end{array}$ & $\begin{array}{l}-0.0176^{* * *} \\
(0.0051)\end{array}$ & $\begin{array}{l}-0.0526^{* * *} \\
(0.0037)\end{array}$ & $\begin{array}{l}-0.0742^{* * *} \\
(0.0053)\end{array}$ \\
\hline GMT21_JST06 & $\begin{array}{l}-0.0145^{* * *} \\
(0.0031)\end{array}$ & $\begin{array}{l}-0.0195^{* * *} \\
(0.0041)\end{array}$ & $\begin{array}{l}-0.0278^{* * *} \\
(0.0051)\end{array}$ & $\begin{array}{l}-0.0052 \\
(0.0049)\end{array}$ & $\begin{array}{l}-0.0301^{* * *} \\
(0.0038)\end{array}$ & $\begin{array}{l}-0.0494^{* * *} \\
(0.0054)\end{array}$ \\
\hline GMT22_JST07 & $\begin{array}{l}-0.0079^{*} \\
(0.0032)\end{array}$ & $\begin{array}{l}-0.0144^{* * *} \\
(0.0042)\end{array}$ & $\begin{array}{l}-0.0239^{* * *} \\
(0.0051)\end{array}$ & $\begin{array}{c}-0.0028 \\
(0.0050)\end{array}$ & $\begin{array}{l}-0.0109^{* *} \\
(0.0037)\end{array}$ & $\begin{array}{l}-0.0256^{* * *} \\
(0.0054)\end{array}$ \\
\hline
\end{tabular}


Table 4 (continued)

\begin{tabular}{|c|c|c|c|c|c|c|}
\hline & \multicolumn{2}{|l|}{ Coincheck } & \multicolumn{2}{|l|}{ BtcBox } & \multicolumn{2}{|l|}{ bitFlyer } \\
\hline & AVG & CR & AVG & CR & AVG & $\mathrm{CR}$ \\
\hline & (1) & $(2)$ & (1) & (2) & (1) & (2) \\
\hline \multirow[t]{2}{*}{ GMT23_JST08 } & -0.0048 & -0.0056 & $-0.0106^{*}$ & 0.0053 & -0.0040 & $-0.0165^{* *}$ \\
\hline & $(0.0031)$ & $(0.0042)$ & $(0.0049)$ & $(0.0048)$ & $(0.0038)$ & $(0.0055)$ \\
\hline \multirow[t]{2}{*}{ logMeanp } & $-0.0031^{* * *}$ & $0.0041^{* * *}$ & $0.0152^{* * *}$ & -0.0007 & $0.0500^{* * *}$ & $0.0378^{* * *}$ \\
\hline & $(0.0009)$ & $(0.0012)$ & $(0.0009)$ & $(0.0009)$ & $(0.0020)$ & $(0.0029)$ \\
\hline \multirow[t]{2}{*}{ logCount } & $-0.0060^{* * *}$ & $0.0069^{* * *}$ & $-0.0478^{* * *}$ & $-0.0315^{* * *}$ & $-0.0550^{* * *}$ & $-0.0283^{* * *}$ \\
\hline & $(0.0008)$ & $(0.0010)$ & $(0.0008)$ & $(0.0008)$ & $(0.0019)$ & $(0.0027)$ \\
\hline \multirow[t]{2}{*}{ logVolsum } & $0.0017^{* *}$ & $-0.0038^{* * *}$ & $-0.0175^{* * *}$ & $-0.0291^{* * *}$ & $0.0531^{* * *}$ & $0.0319^{* * *}$ \\
\hline & $(0.0005)$ & $(0.0007)$ & $(0.0006)$ & $(0.0006)$ & $(0.0015)$ & $(0.0021)$ \\
\hline \multirow[t]{2}{*}{ Rangep } & $0.3730^{* * *}$ & $0.3923^{* * *}$ & $1.3696^{* * *}$ & $1.2711^{* * *}$ & $1.5050^{* * *}$ & $0.5059^{* * *}$ \\
\hline & $(0.0244)$ & $(0.0329)$ & $(0.0476)$ & $(0.0470)$ & $(0.0714)$ & $(0.1030)$ \\
\hline \multirow[t]{2}{*}{ RV } & $1.3628^{* * *}$ & $1.1708^{* * *}$ & -0.0144 & -0.0253 & $-0.3315^{* *}$ & $-0.6889^{* * *}$ \\
\hline & $(0.0680)$ & $(0.0902)$ & $(0.0142)$ & $(0.0139)$ & $(0.1284)$ & $(0.1858)$ \\
\hline N & 46,064 & 46,064 & 45,595 & 45,595 & 15,746 & 15,746 \\
\hline Log likelihood & $42,027.86$ & $29,193.41$ & $17,229.4$ & $17,665.75$ & $19,677.46$ & $13,887.94$ \\
\hline Wald Chi2(28) & $2153.47^{* * *}$ & $2053.13^{* * *}$ & $14,495.64^{* * *}$ & $14,804.75^{* * *}$ & $5761.30 * * *$ & $2379.51^{* * *}$ \\
\hline
\end{tabular}

This table reports the regression results of the hourly price clustering degree on 23 hour dummies with control variables. AVG represents the simple average of DIGIT00, while CR (concentration ratio) refers to the volume-weighted average of DIGIT00. Standard errors are reported in parentheses. The number of observations (N), log likelihood, and Chi squared (Chi2) are also reported. Data from bitFlyer in regressions span continuously from August 1, 2017 to May 26, 2019, whereas data from Coincheck and BtcBox are sampled from January 1, 2015 to April 30, 2020. ***, **, and * denote statistical significance at the $0.1 \%, 1 \%$, and $5 \%$ levels, respectively

comparisons of price clustering between hour intervals have not been conducted. To address this concern, this study uses the Dunn's test (Dunn 1964) with a Bonferroni adjustment to perform nonparametric pairwise comparisons of AVG/CR by the hour, as shown in the "Additional file 1". The null hypothesis of Dunn's test is that the possibility of observation in one group that is greater than observation from another group equals to 0.5 (Dinno 2015). Specifically, Dunn's $z$-test statistic and $p$-value are reported in each table. If the $p$-value is less than the half of the alpha, then the null hypothesis is rejected at the statistical significance level of the alpha. For example, in the comparison of AVG from Coinchek by hour, the $z$-test statistic of JST02 and JST09 is 8.2726, and the null hypothesis that the possibility of observing AVG during JST02 which is greater than AVG during JST09 equals to 0.5 is rejected at the $5 \%$ significance level (alpha=5\%).

According to Dunn' test on AVG/CR, the nonparametric pairwise comparisons show similar results as those from the regression method. First, results of Dunn's test on AVG/ CR of Coincheck indicate that the null hypotheses of pairwise comparisons of AVG/ CR between hour intervals from 2:00 to 7:59 JST and other hour intervals are generally rejected at the $5 \%$ significance level. In other words, the scales of price clustering indexed by AVG/CR of Coincheck from 2:00 to 7:59 JST are generally statistically different from those of other hour intervals. Second, with respect to BtcBox, most of the AVG and CR from 2:00 to 7:59 JST are also statistically different from those of other hour intervals. Third, results of Dunn's test indicate that the AVG/CR of bitFlyer is significantly different between the interval of 0:00 to 7:59 JST and other trading intervals. Overall, the nonparametric pairwise comparisons from Dunn's test suggest that the scales of BTC/JPY 
Table 5 The scale of price clustering when hourly Count exceeds 1,000

\begin{tabular}{|c|c|c|c|c|c|c|}
\hline & \multicolumn{2}{|l|}{ Coincheck } & \multicolumn{2}{|l|}{ BtcBox } & \multicolumn{2}{|l|}{ bitFlyer } \\
\hline & AVG & CR & AVG & CR & AVG & CR \\
\hline & (1) & $(2)$ & (1) & (2) & (1) & $(2)$ \\
\hline \multirow[t]{2}{*}{ Intercept } & $-0.0966^{* * *}$ & $-0.2050^{* * *}$ & $0.1327^{* * *}$ & $0.0781^{* * *}$ & $-0.3952^{* * *}$ & $-0.1192^{* * *}$ \\
\hline & $(0.0054)$ & $(0.0145)$ & $(0.0129)$ & $(0.0098)$ & $(0.0243)$ & $(0.0326)$ \\
\hline \multirow[t]{2}{*}{ GMT01_JST10 } & 0.0005 & 0.0022 & 0.0068 & 0.0033 & $0.0119^{* *}$ & $0.0243^{* * *}$ \\
\hline & $(0.0013)$ & $(0.0036)$ & $(0.0045)$ & $(0.0027)$ & $(0.0044)$ & $(0.0063)$ \\
\hline \multirow[t]{2}{*}{ GMT02_JST11 } & -0.0008 & -0.0015 & 0.0085 & 0.0035 & 0.0030 & 0.0047 \\
\hline & $(0.0013)$ & $(0.0035)$ & $(0.0051)$ & $(0.0032)$ & $(0.0042)$ & $(0.0058)$ \\
\hline \multirow[t]{2}{*}{ GMT03_JST12 } & -0.0003 & 0.0010 & 0.0037 & 0.0033 & $0.0145^{* * *}$ & $0.0159 * *$ \\
\hline & $(0.0013)$ & $(0.0036)$ & $(0.0041)$ & $(0.0031)$ & $(0.0043)$ & $(0.0060)$ \\
\hline \multirow[t]{2}{*}{ GMT04_JST13 } & -0.0000 & 0.0035 & 0.0056 & 0.0036 & $0.0102^{*}$ & $0.0174^{* *}$ \\
\hline & $(0.0013)$ & $(0.0036)$ & $(0.0042)$ & $(0.0032)$ & $(0.0043)$ & $(0.0060)$ \\
\hline \multirow[t]{2}{*}{ GMT05_JST14 } & 0.0003 & 0.0056 & -0.0017 & -0.0016 & 0.0025 & 0.0046 \\
\hline & $(0.0013)$ & $(0.0036)$ & $(0.0030)$ & $(0.0022)$ & $(0.0043)$ & $(0.0059)$ \\
\hline \multirow[t]{2}{*}{ GMT06_JST15 } & 0.0021 & $0.0074^{*}$ & -0.0017 & -0.0023 & 0.0082 & $0.0144^{*}$ \\
\hline & $(0.0014)$ & $(0.0037)$ & $(0.0033)$ & $(0.0022)$ & $(0.0043)$ & $(0.0061)$ \\
\hline \multirow[t]{2}{*}{ GMT07_JST16 } & $0.0030^{*}$ & $0.0089^{*}$ & -0.0041 & $-0.0052^{* *}$ & $0.0101^{*}$ & $0.0135^{*}$ \\
\hline & $(0.0014)$ & $(0.0037)$ & $(0.0030)$ & $(0.0020)$ & $(0.0044)$ & $(0.0060)$ \\
\hline \multirow[t]{2}{*}{ GMT08_JST17 } & 0.0025 & $0.0088^{*}$ & -0.0051 & $-0.0052^{* *}$ & 0.0039 & 0.0080 \\
\hline & $(0.0013)$ & $(0.0035)$ & $(0.0028)$ & $(0.0019)$ & $(0.0042)$ & $(0.0058)$ \\
\hline \multirow[t]{2}{*}{ GMT09_JST18 } & $0.0028^{*}$ & $0.0089^{*}$ & -0.0040 & $-0.0044^{*}$ & 0.0058 & 0.0037 \\
\hline & $(0.0013)$ & $(0.0036)$ & $(0.0031)$ & $(0.0020)$ & $(0.0043)$ & $(0.0061)$ \\
\hline \multirow[t]{2}{*}{ GMT10_JST19 } & $0.0030^{*}$ & $0.0076^{*}$ & $-0.0064^{*}$ & $-0.0050^{*}$ & 0.0038 & -0.0026 \\
\hline & $(0.0013)$ & $(0.0036)$ & $(0.0028)$ & $(0.0021)$ & $(0.0042)$ & $(0.0056)$ \\
\hline \multirow[t]{2}{*}{ GMT11_JST20 } & $0.0046^{* * *}$ & $0.0086^{*}$ & -0.0041 & $-0.0048^{*}$ & 0.0046 & -0.0053 \\
\hline & $(0.0013)$ & $(0.0035)$ & $(0.0029)$ & $(0.0019)$ & $(0.0041)$ & $(0.0056)$ \\
\hline \multirow[t]{2}{*}{ GMT12_JST21 } & $0.0076^{* * *}$ & $0.0125^{* * *}$ & -0.0014 & -0.0028 & 0.0066 & -0.0061 \\
\hline & $(0.0013)$ & $(0.0035)$ & $(0.0037)$ & $(0.0024)$ & $(0.0041)$ & $(0.0055)$ \\
\hline \multirow[t]{2}{*}{ GMT13_JST22 } & $0.0077^{* * *}$ & $0.0122^{* * *}$ & -0.0030 & -0.0036 & $0.0111^{*}$ & -0.0011 \\
\hline & $(0.0013)$ & $(0.0035)$ & $(0.0031)$ & $(0.0021)$ & $(0.0043)$ & $(0.0056)$ \\
\hline \multirow[t]{2}{*}{ GMT14_JST23 } & $0.0065^{* * *}$ & $0.0111^{* *}$ & -0.0049 & $-0.0048^{*}$ & 0.0034 & -0.0071 \\
\hline & $(0.0013)$ & $(0.0035)$ & $(0.0030)$ & $(0.0021)$ & $(0.0043)$ & $(0.0057)$ \\
\hline \multirow[t]{2}{*}{ GMT15_JST00 } & 0.0018 & 0.0015 & -0.0017 & -0.0037 & $-0.0122^{* *}$ & $-0.0251^{* * *}$ \\
\hline & $(0.0013)$ & $(0.0034)$ & $(0.0036)$ & $(0.0023)$ & $(0.0043)$ & $(0.0057)$ \\
\hline \multirow[t]{2}{*}{ GMT16_JST01 } & -0.0022 & -0.0061 & -0.0020 & -0.0035 & $-0.0301^{* * *}$ & $-0.0419^{* * *}$ \\
\hline & $(0.0013)$ & $(0.0034)$ & $(0.0035)$ & $(0.0021)$ & $(0.0042)$ & $(0.0057)$ \\
\hline \multirow[t]{2}{*}{ GMT17_JST02 } & $-0.0074^{* * *}$ & $-0.0183^{* * *}$ & 0.0005 & -0.0031 & $-0.0489^{* * *}$ & $-0.0676^{* * *}$ \\
\hline & $(0.0013)$ & $(0.0035)$ & $(0.0044)$ & $(0.0025)$ & $(0.0042)$ & $(0.0056)$ \\
\hline GMT18_JST03 & $-0.0118^{* * *}$ & $-0.0300^{* * *}$ & $-0.0085^{* *}$ & $-0.0079^{* * *}$ & $-0.0549^{* * *}$ & $-0.0741^{* * *}$ \\
\hline & $(0.0013)$ & $(0.0035)$ & $(0.0029)$ & $(0.0019)$ & $(0.0044)$ & $(0.0059)$ \\
\hline GMT19_JST04 & $-0.0147^{* * *}$ & $-0.0405^{* * *}$ & $-0.0096^{* * *}$ & $-0.0087^{* * *}$ & $-0.0537^{* * *}$ & $-0.0783^{* * *}$ \\
\hline & $(0.0013)$ & $(0.0034)$ & $(0.0026)$ & $(0.0018)$ & $(0.0047)$ & $(0.0064)$ \\
\hline GMT20_JST05 & $-0.0125^{* * *}$ & $-0.0318^{* * *}$ & $-0.0088^{* * *}$ & $-0.0077^{* * *}$ & $-0.0534^{* * *}$ & $-0.0728^{* * *}$ \\
\hline & $(0.0013)$ & $(0.0034)$ & $(0.0026)$ & $(0.0018)$ & $(0.0043)$ & $(0.0058)$ \\
\hline GMT21_JST06 & $-0.0062^{* * *}$ & $-0.0164^{* * *}$ & $-0.0078^{* *}$ & $-0.0074^{* * *}$ & $-0.0329^{* * *}$ & $-0.0496^{* * *}$ \\
\hline & $(0.0013)$ & $(0.0035)$ & $(0.0029)$ & $(0.0020)$ & $(0.0043)$ & $(0.0058)$ \\
\hline GMT22_JST07 & $-0.0048^{* * *}$ & $-0.0127^{* * *}$ & $-0.0077^{* *}$ & $-0.0073^{* * *}$ & $-0.0138^{* * *}$ & $-0.0281^{* * *}$ \\
\hline & $(0.0013)$ & $(0.0036)$ & $(0.0027)$ & $(0.0018)$ & $(0.0041)$ & $(0.0058)$ \\
\hline
\end{tabular}


Table 5 (continued)

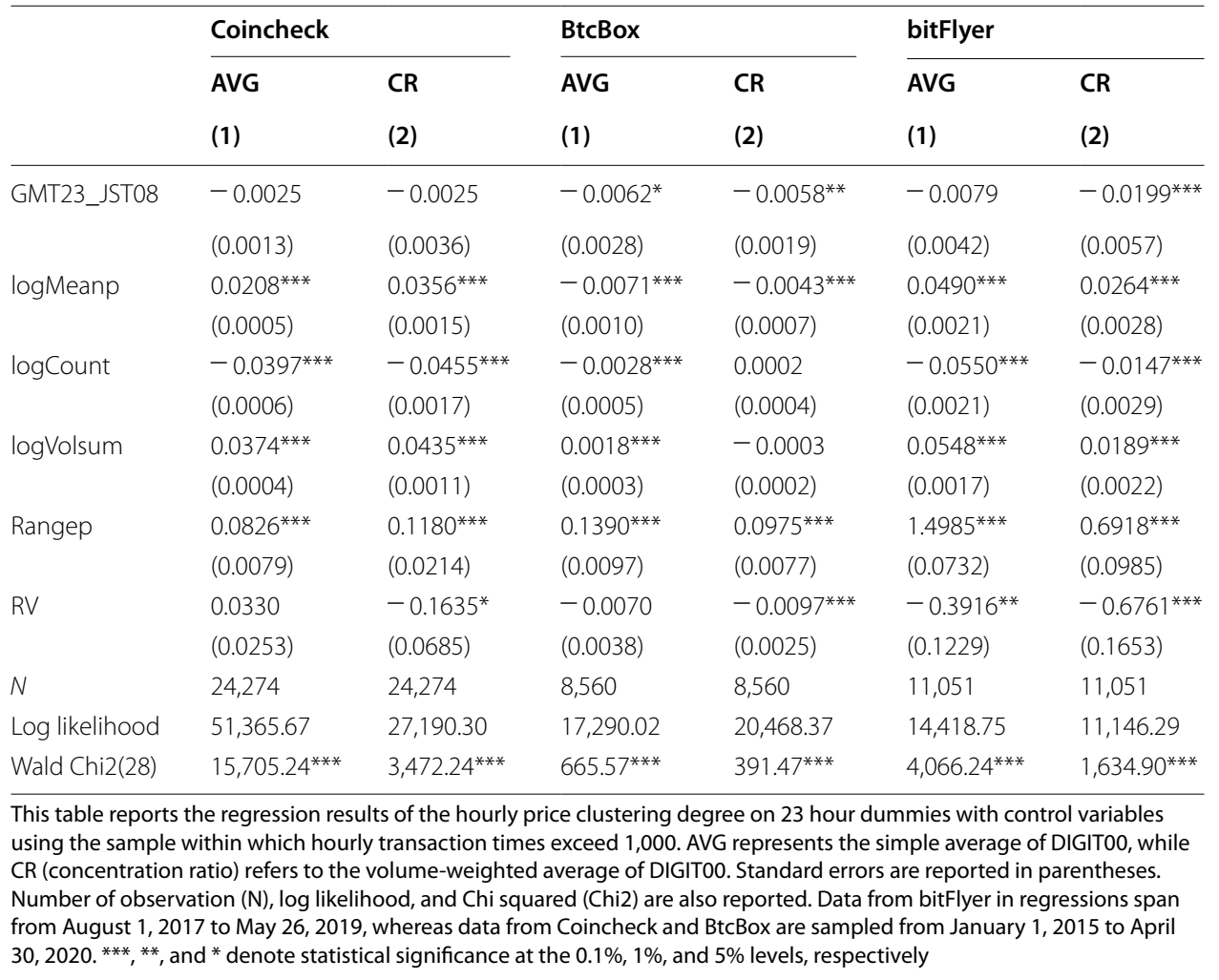

price clustering indexed by AVG and CR are generally lower from 2:00 to 7:59 JST over the three online crypto exchanges, which is consistent with the empirical results from the parametric method.

\section{Discussions}

\section{Possible explanations}

Figure 6 presents the mean hourly volume in BTC and the transaction counts. Specifically, the hourly transaction volume and counts tend to be lower during the interval of 2:00 to 7:59 JST as shown in Fig. 6. Afterward, from 9:00 to 9:59 JST, transaction volume and counts apparently increase. Then, hourly volume and counts tend to increase from 18:00 to 22:59 JST on Coincheck and bitFlyer, whereas for BtcBox, the volume is inclined to decline throughout the day after JST11, and hourly counts remain stable on the whole. The increased hourly volume and transaction counts outside typical working hours suggest that retail investors play an important role in the transactions on Coincheck and bitFlyer, while retail investors dominate the BtcBox because transactions seem to be constant without the preferred transaction time during the sample period (Baur et al. 2019). 

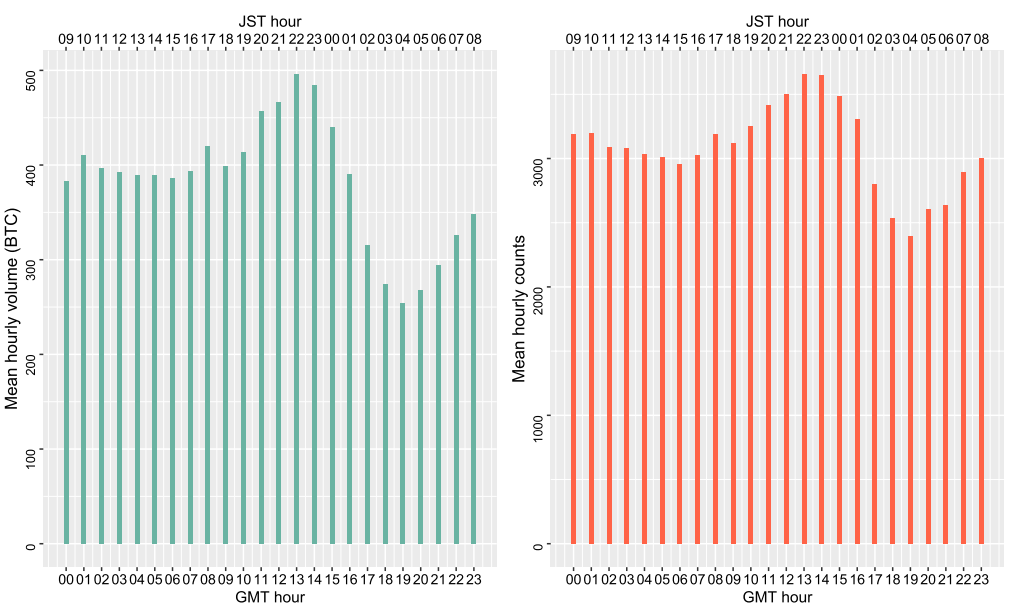

(a) Coincheck
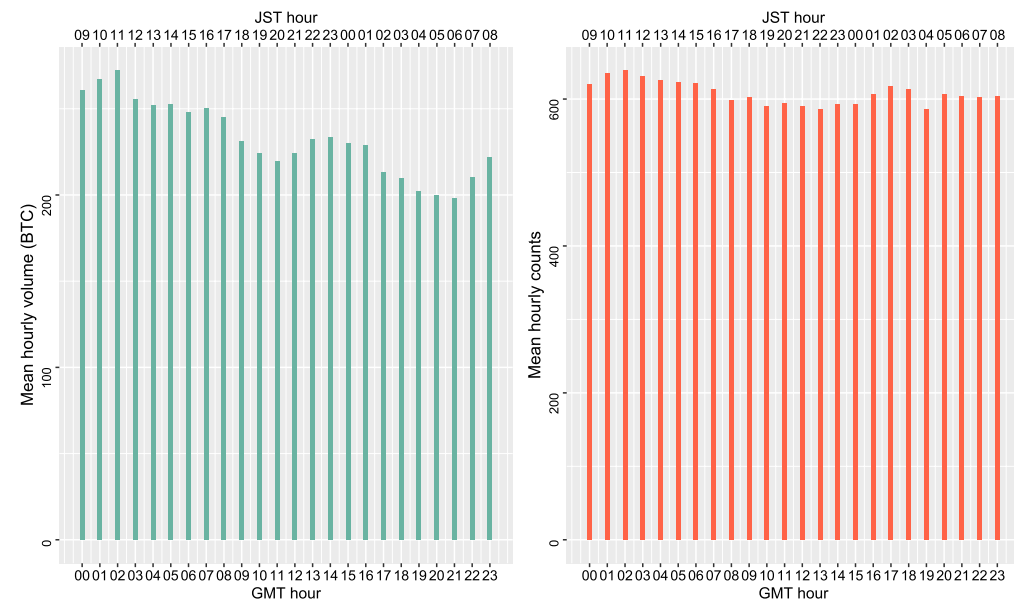

(b) BtcBox
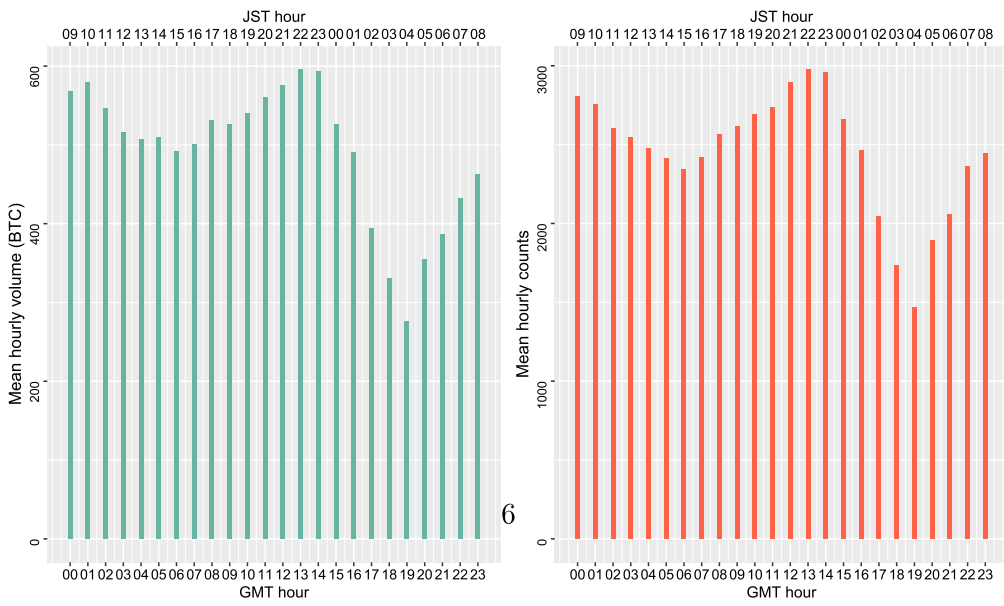

(c) bitFlyer

Fig. 6 Mean hourly volume and transaction counts. This figure reports the mean values of hourly volume in BTC and transaction counts during the sample period. Hours in JST and GMT are presented in top and bottom X-axes 
This study attempts to explain the phenomenon of lower price clustering indexed by AVG and CR from 2:00 to 7:59 JST with two possible explanations. The first hypothesis is that investors are heterogeneous over time of the day. As transactions in online crypto exchanges are observed from day to night, this indicates the presence of investors throughout the day. However, some investors, such as institutional investors, cannot be online throughout the day. A possible explanation for the lower price clustering from 2:00 to 7:59 JST is that investors active in the daytime prefer round prices, whereas investors awake at night are less likely to strike at round prices. Further, although a previous study by Davis et al. (2014) has shown that institutional or sophisticated investors could help reduce price clustering, price clustering in the daytime does not appear to be lower with the participation of institutional investors because retail investors account for a large proportion of BTC transactions (Baur et al. 2019).

The second hypothesis is that the information environment is different during daytime and nighttime. Although online crypto exchanges operate without opening and closing, traditional asset markets are still in the normal routine. Also, information related to other asset markets (e.g., stock market) could still impact the decision-making process of investors in daytime. However, investors awake at night, especially after 0:00 JST, are in a different environment with less unrelated information. As discussed in Baig et al. (2020) that the opacity of a firm is positively associated with price clustering, the information environment of less noise at night could help reduce price clustering in BTC/JPY.

\section{Strategic pricing}

Strategic pricing or strategic clustering refers to the behavior that investors ask at prices just below round numbers and bid at prices just above round numbers. Strategic pricing behavior takes advantage of the price clustering phenomenon to get execution priority or a better price (Aşçloğlu et al. 2007; Bhattacharya et al. 2012). It has been confirmed to exist in multiple stock markets (Sonnemans 2006; Aşçloğlu et al. 2007; Verousis and Ap Gwilym 2014; Chen 2018; Bhattacharya et al. 2012). Similarly, strategic pricing has also been found to exist in the BTC/USD market that prices ending at \$.01 and \$.99 exceed $2 \%$ by Baig et al. (2019a). In this study, prices ending with ' 99 ' and '01' account for more than $2 \%$ on the three online crypto exchanges, as shown in Table 2, which means that strategic pricing is also present in the BTC/JPY market from the data of the three online crypto exchanges.

The political implication drawn from the empirical analysis conducted in this study is that the strategic pricing around numbers ending with ' 00 ' is more appropriate before 2:00 JST, while prices may be more efficient during some specific hours. First, when trade sizes and counts of clustered prices are on the increase from 9:00 JST, the bid or ask prices at the numbers ending with '01' or '99' could capitalize on round prices to strike a deal at a relatively low cost. Second, due to the significantly lower level of price clustering, prices are relatively more efficient from 2:00 to 7:59 JST. Although the market efficiency of BTC has been studied in depth (see Urquhart 2016; Nadarajah and 
Chu 2017; Bariviera 2017; Kristoufek 2018; Sigaki et al. 2019; Zargar and Kumar 2019), the difference in market efficiency of BTC between day and night has not been further explored. Hence, it is necessary to consider the difference in the price clustering or inefficiency of BTC between day and night regarding investment risk.

\section{High-frequency data analysis}

Recently, high-frequency data of cryptocurrencies have been used to analyze the cryptocurrency markets which are active 24/7. In addition to the market (in)efficiency (e.g., Zhang et al. 2019; Chu et al. 2019; Corbet et al. 2019; Aslan and Sensoy 2020) and interdependencies within cryptocurrency markets (e.g., Sifat et al. 2019; Yarovaya and Zięba 2020), researches on market microstructure of cryptocurrencies with high-frequency data have reported some interesting findings. Baur et al. (2019) presented that intraday volumes of BTC were higher when potential investors were inclined to be awake on some crypto exchanges. Similarly, Petukhina et al. (2021) investigated the intraday patterns of returns, volumes, and volatilities with high-frequency trading data of multiple cryptocurrencies in the European cryptocurrency markets. And intraday activity patterns observed by Petukhina et al. (2021) suggest that instead of machines, humans still play an important role in the European cryptocurrency markets. Consistent with Baur et al. (2019) and Petukhina et al. (2021), intraday patterns of price clustering in BTC/JPY observed in this study indicate that human behavior also has an important impact on market activity in the BTC/JPY market.

\section{Conclusions}

In this study, tick-by-tick transaction data were applied to examine whether price clustering also exists in BTC denominated in JPY on Coincheck, BtcBox, and bitFlyer-the prices that are in integers. In addition, an investigation was conducted on how the extent of price clustering varies throughout a trading day. First, as the price clustering at round numbers in BTC denominated in USD on Bitstamp has been reported by Urquhart (2017) and Mbanga (2019), similarly, the price clustering at numbers ending with '00' occurs in BTC denominated in JPY. Second, empirical results have demonstrated that the scales of BTC/JPY price clustering indexed by AVG and CR significantly decline from 2:00 to 7:59 JST on the whole. Moreover, this phenomenon is unlikely to be explained by the negotiation hypothesis. Finally, this study contributes to the emerging literature on price clustering and investor behavior.

\section{Appendix}

See Fig. 7. 

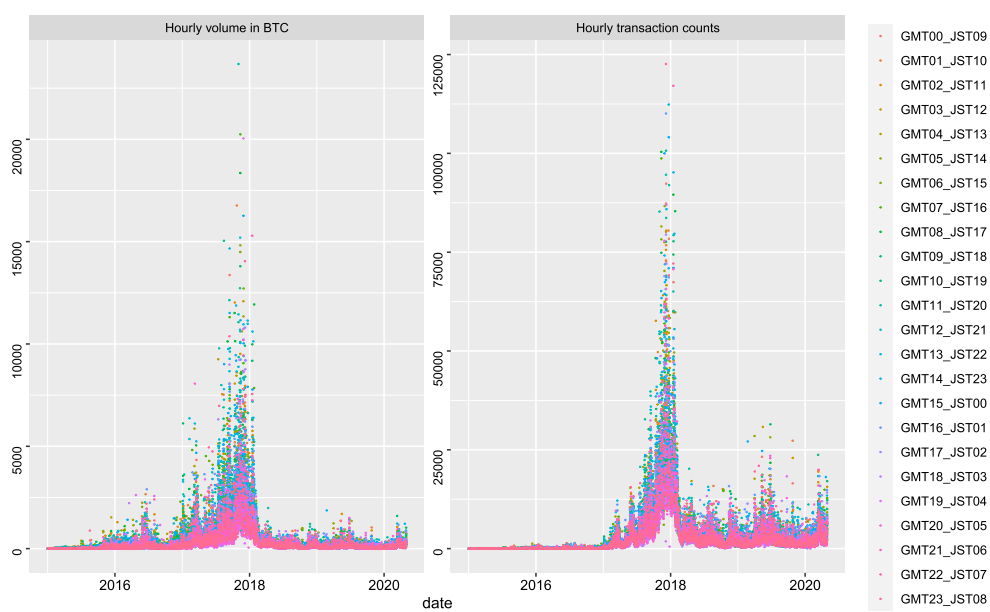

(a) Coincheck
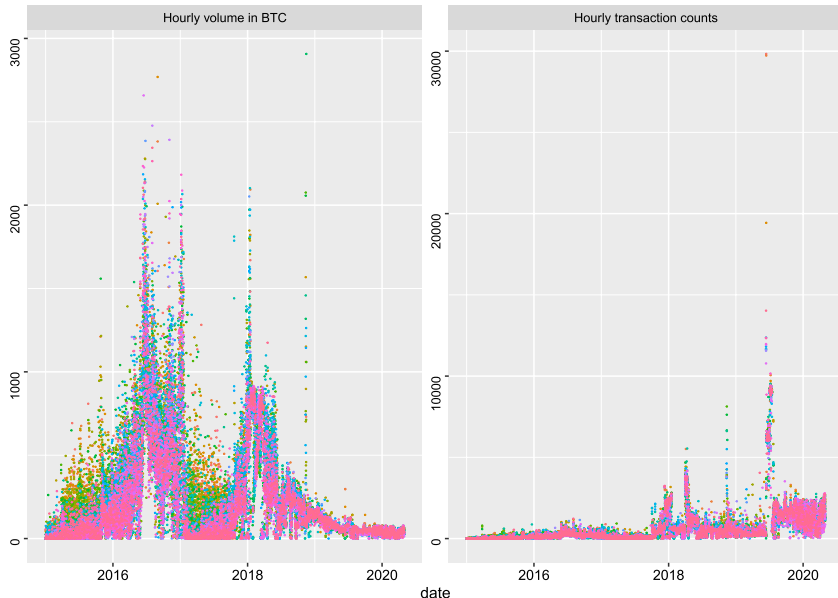

(b) BtcBox
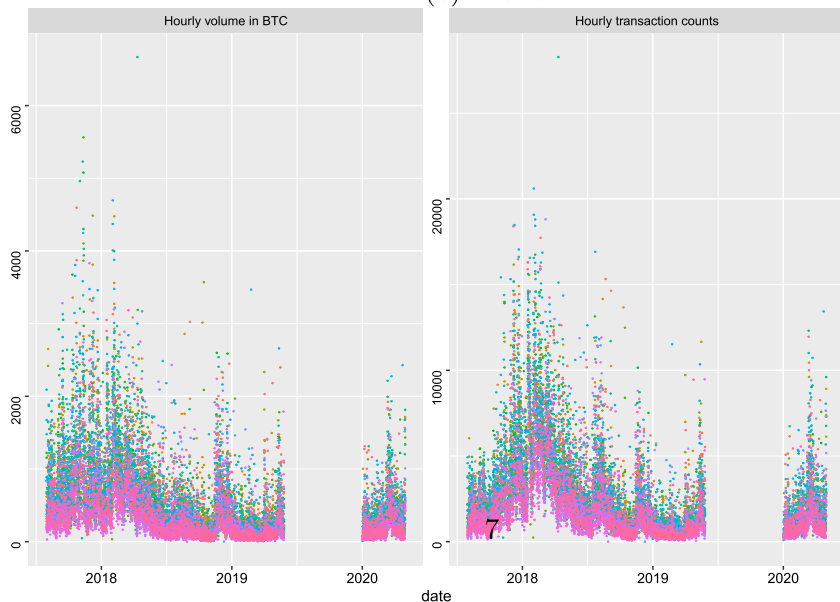

CMTOO JSTO

GMT01_JST10

GMTO2_SST11

GMT03_JST12

GMT04_JST13

GMT05_JST14

GMT06_JST15

GMT07_JST16

GMT08_JST17

GMT09_JST18

GMT10_JST19

GMT11_JST20

GMT12_JST21

GMT13 JST22

GMT14_JST23

GMT15_JSTO0

GMT16_JST01

GMT17_JSTO2

GMT18_JSTO3

GMT19_JSTO4

GMT20 JSTO5

GMT20JSTOS

GMT21_JSTO6

GMT22_JST07

(c) bitFlyer

Fig. 7 Hourly volume and transaction counts of BTC/JPY. This figure presents hourly volume in BTC and hourly transaction counts of three online crypto exchanges on a daily basis during each sample period 


\section{Supplementary Information}

The online version contains supplementary material available at https://doi.org/10.1186/s40854-021-00307-4.

Additional file 1. Results of Dunn's test on AVG/CR for each crypto exchange.

\section{Acknowledgements}

We'd like to thank editors for the consideration of this study. And we appreciate valuable comments and constructive suggestions from all anonymous referees. This study is based on part of the first author's doctoral dissertation.

\section{Author contributions}

DM: conceptualization, data collection and analysis, and the first draft. HT: review, revision, and supervision. Both authors read and approved the final manuscript.

\section{Authors' Information}

Donglian Ma is currently a postdoctoral research associate at Shenzhen Audencia Business School, Shenzhen University. Her current research focuses on investor behavior and market microstructure

Hisashi Tanizaki is a professor at Graduate School of Economics, Osaka University. His research interests include estimation and inference on simulation-based econometrics.

\section{Funding}

This research is supported by the Japan Society for the Promotion of Science, Grant-in-Aid for Scientific Research (C) $17 \mathrm{~K} 03657$.

Availability of data and materials

Data supporting this study is obtained from http://api.bitcoincharts.com/v1/csv/

\section{Declarations}

\section{Competing interests}

The authors declare that there is no competing interests.

\section{Author details}

${ }^{1}$ Shenzhen Audencia Business School, Shenzhen University, Shenzhen 518060, China. ${ }^{2}$ Graduate School of Economics, Osaka University, Osaka 560-0043, Japan.

Received: 26 August 2020 Accepted: 14 November 2021

Published online: 01 January 2022

\section{References}

Aggarwal R, Lucey BM (2007) Psychological barriers in gold prices? Rev Financial Econ 16(2):217-230. https://doi.org/10. 1016/j.rfe.2006.04.001

Ahn HJ, Cai J, Cheung YL (2005) Price clustering on the limit-order book: evidence from the Stock Exchange of Hong Kong. J Financial Mark 8(4):421-451. https://doi.org/10.1016/j.finmar.2005.07.001

Aitken M, Izan HY, Buckland C, Walter T, Brown P (1996) Price clustering on the Australian Stock Exchange. Pac Basin Finance J 4(2-3):297-314. https://doi.org/10.1016/0927-538x(96)00016-9

Andersen TG, Bollerslev T (1998) Answering the skeptics: yes, standard volatility models do provide accurate forecasts. Int Econ Rev 39(4):885-905. https://doi.org/10.2307/2527343

Ap Gwilym O, Clare A, Thomas S (1998) Extreme price clustering in the London equity index futures and options markets. J Bank Finance 22(9):1193-1206. https://doi.org/10.1016/S0378-4266(98)00054-5

Aşçloğlu A, Comerton-Forde C, Mclnish TH (2007) Price clustering on the Tokyo stock exchange. Financial Rev 42(2):289-301. https://doi.org/10.1111/j.1540-6288.2007.00172.x

Aslan A, Sensoy A (2020) Intraday efficiency-frequency nexus in the cryptocurrency markets. Finance Res Lett 35:101298. https://doi.org/10.1016/j.frl.2019.09.013

Baig AS, Sabah N (2020) Does short selling affect the clustering of stock prices? Q Rev Econ Finance 76:270-277. https://doi. org/10.1016/j.gref.2019.08.008

Baig A, Blau BM, Sabah N (2019a) Price clustering and sentiment in bitcoin. Finance Res Lett 29:111-116. https://doi.org/10. 1016/j.frl.2019.03.013

Baig AS, Blau BM, Whitby RJ (2019b) Price clustering and economic freedom: the case of cross-listed securities. J Multinatl Financial Manag 50:1-12. https://doi.org/10.1016/j.mulfin.2019.04.002

Baig A, Blau BM, Griffith TG (2020) Firm opacity and the clustering of stock prices: the case of financial intermediaries. J Financial Serv Res. https://doi.org/10.1007/s10693-020-00341-w

Ball CA, Torous WN, Tschoegl AE (1985) The degree of price resolution: the case of the gold market. J Future Mark 5(1):29-43. https://doi.org/10.1002/fut.3990050105

Bariviera AF (2017) The inefficiency of Bitcoin revisited: a dynamic approach. Econ Lett 161:1-4. https://doi.org/10.1016/j. econlet.2017.09.013

Baur DG, Cahill D, Godfrey K, Liu Z (2019) Bitcoin time-of-day, day-of-week and month-of-year effects in returns and trading volume. Financial Res Lett 31:78-92. https://doi.org/10.1016/j.frl.2019.04.023 
Bhattacharya U, Holden CW, Jacobsen S (2012) Penny wise, dollar foolish: buy-sell imbalances on and around round numbers. Manag Sci 58(2):413-431. https://doi.org/10.1287/mnsc.1110.1364

Blau BM, Griffith TG (2016) Price clustering and the stability of stock prices. J Bus Res 69(10):3933-3942. https://doi.org/10. 1016/j.jbusres.2016.06.008

Brooks R, Harris E, Joymungul Y (2013) Price clustering in Australian water markets. Appl Econ 45(6):677-685. https://doi.org/ 10.1080/00036846.2011.610747

Brown A, Yang F (2016) Limited cognition and clustered asset prices: evidence from betting markets. J Financial Mark 29:27-46. https://doi.org/10.1016/j.finmar.2015.10.003

Chen T (2018) Round-number biases and informed trading in global markets. J Bus Res 92:105-117. https://doi.org/10.1016/j. jbusres.2018.07.027

Christie WG, Schultz PH (1994) Why do NASDAQ market makers avoid odd-eighth quotes? J Finance 49(5):1813-1840. https://doi.org/10.1111/j.1540-6261.1994.tb04782.x

Chu J, Zhang Y, Chan S (2019) The adaptive market hypothesis in the high frequency cryptocurrency market. Int Rev Financ Anal 64:221-231. https://doi.org/10.1016/j.irfa.2019.05.008

Chun H, Chiang S (2006) Price clustering in E-mini and floor-traded index futures. J Future Mark 26(3):269-295. https://doi. org/10.1002/fut.20196

Corbet S, Eraslan V, Lucey B, Sensoy A (2019) The effectiveness of technical trading rules in cryptocurrency markets. Finance Res Lett 31:32-37. https://doi.org/10.1016/j.frl.2019.04.027

Das S, Kadapakkam PR (2020) Machine over mind? Stock price clustering in the era of algorithmic trading. N Am J Econ Finance 51:100831. https://doi.org/10.1016/..najef.2018.08.014

Davis RL, Van Ness BF, Van Ness RA (2014) Clustering of trade prices by high-frequency and non-high-frequency trading firms. Financial Rev 49(2):421-433. https://doi.org/10.1111/fire.12042

Dias JG, Vermunt JK, Ramos S (2015) Clustering financial time series: new insights from an extended hidden Markov model. Eur J Oper Res 243(3):852-864. https://doi.org/10.1016/j.ejor.2014.12.041

Dinno A (2015) Nonparametric pairwise multiple comparisons in independent groups using Dunn's test. Stata J 15(1):292300. https://doi.org/10.1177/1536867×1501500117

Dowling M, Cummins M, Lucey BM (2016) Psychological barriers in oil futures markets. Energy Econ 53:293-304. https://doi org/10.1016/j.eneco.2014.03.022

Dunn OJ (1964) Multiple comparisons using rank sums. Technometrics 6(3):241-252. https://doi.org/10.1080/00401706.1964. 10490181

Eross A, McGroarty F, Urquhart A, Wolfe S (2019) The intraday dynamics of bitcoin. Res Int Bus Finance 49:71-81. https://doi. org/10.1016/j.ribaf.2019.01.008

Fujiki H (2020) Who adopts crypto assets in Japan? Evidence from the 2019 financial literacy survey. J Jpn Int Econ 58:101107. https://doi.org/10.1016/j.jie.2020.101107

Fujiki H, Tanaka M (2018) How do we choose to pay using evolving retail payment technologies? Evidence from Japan. J Jpn Int Econ 49:85-99. https://doi.org/10.1016/j.jjie.2018.05.001

Hairudin A, Sifat IM, Mohamad A, YusofY (2020) Cryptocurrencies: a survey on acceptance, governance and market dynamics. Int J Finance Econ. https://doi.org/10.1002/ijfe.2392

Harris L (1991) Stock price clustering and discreteness. Rev Financial Stud 4(3):389-415. https://doi.org/10.1093/rfs/4.3.389

Hu B, Mclnish T, Miller J, Zeng L (2019) Intraday price behavior of cryptocurrencies. Finance Res Lett 28:337-342. https://doi. org/10.1016/j.frl.2018.06.002

Ikenberry DL, Weston JP (2008) Clustering in US stock prices after decimalisation. Eur Financial Manag 14(1):30-54. https://doi. org/10.1111/j.1468-036X.2007.00410.x

Kou G, Peng Y, Wang G (2014) Evaluation of clustering algorithms for financial risk analysis using MCDM methods. Inf Sci 275:1-12. https://doi.org/10.1016/j.ins.2014.02.137

Kristoufek L (2018) On Bitcoin markets (in)efficiency and its evolution. Physica A 503:257-262. https://doi.org/10.1016/j.physa. 2018.02.161

Li X, Li S, Xu C (2020) Price clustering in Bitcoin market—an extension. Finance Res Lett 32:101072. https://doi.org/10.1016/j. frl.2018.12.020

LiT, Kou G, Peng Y, Yu PS (2021) An integrated cluster detection, optimization, and interpretation approach for financial data. IEEE Trans Cybern. https://doi.org/10.1109/tcyb.2021.3109066

Mbanga CL (2019) The day-of-the-week pattern of price clustering in Bitcoin. Appl Econ Lett 26(10):807-811. https://doi.org/ $10.1080 / 13504851.2018 .1497844$

Mitchell J (2001) Clustering and psychological barriers: the importance of numbers. J Future Mark 21(5):395-428. https://doi. org/10.1002/fut.2

Musmeci N, Aste T, Matteo TD (2015) Relation between financial market structure and the real economy: comparison between clustering methods. PLoS ONE. https://doi.org/10.1371/journal.pone.0116201

Nadarajah S, Chu J (2017) On the inefficiency of Bitcoin. Econ Lett 150:6-9. https://doi.org/10.1016/j.econlet.2016.10.033

Nakamoto S (2008) Bitcoin: a peer-to-peer electronic cash system. www.Bitcoin.Org

Narayan PK, Narayan S, Popp S (2011) Investigating price clustering in the oil futures market. Appl Energy 88(1):397-402. https://doi.org/10.1016/j.apenergy.2010.07.034

NiederhofferV (1965) Clustering of stock prices. Oper Res 13(2):258-265. https://doi.org/10.1287/opre.13.2.258

Ohta W (2006) An analysis of intraday patterns in price clustering on the Tokyo Stock Exchange. J Bank Finance 30(3):10231039. https://doi.org/10.1016/j.jbankfin.2005.07.017

Osborne MFM (1962) Periodic structure in the Brownian motion of stock prices. Oper Res 10(3):345-379. https://doi.org/10. 1287/opre.10.3.345

Osborne MFM (1965) The dynamics of stock trading. Econometrica 33(1):88-113. https://doi.org/10.2307/1911890

Palao F, Pardo A (2012) Assessing price clustering in European carbon markets. Appl Energy 92:51-56. https://doi.org/10. 1016/j.apenergy.2011.10.022

Petukhina AA, Reule RCG, Härdle WK (2021) Rise of the machines? Intraday high-frequency trading patterns of cryptocurrencies. Eur J Finance 27(1-2):8-30. https://doi.org/10.1080/1351847X.2020.1789684. arXiv:2009.04200 
Schwartz AL, Van Ness BF, Van Ness RA (2004) Clustering in the futures market: evidence from S\&P 500 futures contracts. J Future Mark 24(5):413-428. https://doi.org/10.1002/fut.10129

Sifat IM, Mohamad A, Mohamed Shariff MSB (2019) Lead-Lag relationship between Bitcoin and Ethereum: evidence from hourly and daily data. Res Int Bus Finance 50:306-321. https://doi.org/10.1016/.j.ribaf.2019.06.012

Sigaki HYD, Perc M, Ribeiro HV (2019) Clustering patterns in efficiency and the coming-of-age of the cryptocurrency market. Sci Rep 9(1440):1-9. https://doi.org/10.1038/s41598-018-37773-3

Sonnemans J (2006) Price clustering and natural resistance points in the Dutch stock market: a natural experiment. Eur Econ Rev 50(8):1937-1950. https://doi.org/10.1016/j.euroecorev.2005.09.001

Sopranzetti BJ, DatarV (2002) Price clustering in foreign exchange spot markets. J Financial Mark 5(4):411-417. https://doi. org/10.1016/S1386-4181(01)00032-5

Urquhart A (2016) The inefficiency of Bitcoin. Econ Lett 148:80-82. https://doi.org/10.1016/j.econlet.2016.09.019

Urquhart A (2017) Price clustering in Bitcoin. Econ Lett 159:145-148. https://doi.org/10.1016/j.econlet.2017.07.035

Verousis T, Ap Gwilym O (2013) Trade size clustering and the cost of trading at the London Stock Exchange. Int Rev Financial Anal 27:91-102. https://doi.org/10.1016/j.irfa.2012.08.007

Verousis T, Ap Gwilym O (2014) The implications of a price anchoring effect at the upstairs market of the London Stock Exchange. Int Rev Financial Anal 32:37-46. https://doi.org/10.1016/j.irfa.2013.12.001

Yarovaya L, Zięba D (2020) Intraday volume-return nexus in cryptocurrency markets: a novel evidence from cryptocurrency classification. SSRN Electron J. https://doi.org/10.2139/ssrn.3711667

Zargar FN, Kumar D (2019) Informational inefficiency of Bitcoin: a study based on high-frequency data. Res Int Bus Finance 47:344-353. https://doi.org/10.1016/.j.ibaf.2018.08.008

Zhang Y, Chan S, Chu J, Nadarajah S (2019) Stylised facts for high frequency cryptocurrency data. Physica A 513:598-612. https://doi.org/10.1016/j.physa.2018.09.042

\section{Publisher's Note}

Springer Nature remains neutral with regard to jurisdictional claims in published maps and institutional affiliations.

\section{Submit your manuscript to a SpringerOpen ${ }^{\odot}$ journal and benefit from:}

- Convenient online submission

Rigorous peer review

Open access: articles freely available online

- High visibility within the field

Retaining the copyright to your article

Submit your next manuscript at $\mathbf{s p r i n g e r o p e n . c o m ~}$ 